\title{
An overview of methodologies for real-time detection, characterisation and tracking of traveling ionospheric disturbances developed in the TechTIDE project
}

\author{
Anna Belehaki ${ }^{1, *}$ Ioanna Tsagouri ${ }^{1}$, David Altadill ${ }^{2}$, Estefania Blanch ${ }^{2,3}$, Claudia Borries ${ }^{4}$, \\ Dalia Buresova $^{5}$, Jaroslav Chum ${ }^{5}$, Ivan Galkin ${ }^{6}$, José Miguel Juan ${ }^{7}$, Antoni Segarra ${ }^{2}$, \\ Cristhian Camilo Timoté ${ }^{7}$, Kostas Tziotziou ${ }^{1}$, Tobias G. W. Verhulst ${ }^{8}$, and Jurgen Watermann ${ }^{9}$ \\ ${ }^{1}$ National Observatory of Athens, IAASARS, 15236 Palaia Penteli, Greece \\ 2 Observatori de l'Ebre (OE), CSIC - Universitat Ramon Llull, 43520 Roquetes, Spain \\ ${ }^{3}$ Departament de Física-EPSEB, UPC Barcelona Tech, 08028 Barcelona, Spain \\ ${ }^{4}$ German Aerospace Center, Institute for Solar-Terrestrial Physics, 17235 Neustrelitz, Germany \\ 5 Institute of Atmospheric Physics, Czech Academy of Sciences, 14100 Prague, Czech Republic \\ ${ }^{6}$ Borealis Designs Ltd., 9000 Varna, Bulgaria \\ 7 gAGE, Universitat Politecnica de Catalunya, 08034 Barcelona, Spain \\ ${ }^{8}$ Royal Meteorological Institute, 1180 Dourbes, Belgium \\ 9 jfwConsult, La Tetrade, 443 Chemin de Pichot, Tourrettes, 83440 Var, France
}

Received 8 April 2020 / Accepted 4 August 2020

\begin{abstract}
The main objective of the TechTIDE project (warning and mitigation technologies for travelling ionospheric disturbances effects) is the development of an identification and tracking system for travelling ionospheric disturbances (TIDs) which will issue warnings of electron density perturbations over large world regions. The TechTIDE project has put in operation a real-time warning system that provides the results of complementary TID detection methodologies and many potential drivers to help users assess the risks and develop mitigation techniques tailored to their applications. The TechTIDE methodologies are able to detect in real time activity caused by both large-scale and medium-scale TIDs and characterize background conditions and external drivers, as an additional information required by the users to assess the criticality of the ongoing disturbances in real time. TechTIDE methodologies are based on the exploitation of data collected in real time from Digisondes, Global Navigation Satellite System (GNSS) receivers and Continuous Doppler Sounding System (CDSS) networks. The results are obtained and provided to users in real time. The paper presents the achievements of the project and discusses the challenges faced in the development of the final TechTIDE warning system.
\end{abstract}

\section{Introduction}

The Earth's upper atmosphere is directly affected by the solar variability, by the near-Earth space dynamics and lower atmosphere phenomena. This results in a complex and dynamic environment influenced by solar radiation, energy transfer, winds, waves, tides, electric, and magnetic fields, and plasma processes. Travelling ionospheric disturbances (TIDs) constitute an important Space Weather effect in the upper atmosphere driven by this complexity. TIDs are plasma density fluctuations that propagate as waves through the ionosphere at a wide range of velocities and frequencies and play an important role in the

\footnotetext{
*Corresponding author: belehaki@noa.gr, abeleha@otenet.gr
}

exchange of momentum and energy between various regions of the upper atmosphere. TIDs are the ionospheric manifestation of internal atmospheric gravity waves (AGW) in the thermosphere (e.g., Hunsucker, 1982; Hocke \& Schlegel, 1996). The vast majority of observations suggests that gravity waves transport momentum and energy from auroral latitudes to middle latitudes (Hocke \& Schlegel, 1996) and can also transfer momentum and energy from the lower to the upper atmosphere. Francis (1975) concluded in his classic review on atmospheric gravity waves that theory and observations imply that "the only natural sources of large-scale TIDs are in the auroral zones". However, some cases of large-scale TIDs (LSTIDs) being launched in the vicinity of the magnetic equator were recently reported (Habarulema et al., 2015, 2016, 2018) although such cases appear to be rare. AGW and consequently TIDs are 
classified according to their wave velocity and period. LSTIDs have horizontal propagation velocities between $300 \mathrm{~m} / \mathrm{s}$ and $1000 \mathrm{~m} / \mathrm{s}$, horizontal wavelengths greater than $1000 \mathrm{~km}$ $(1000-3000 \mathrm{~km})$ and periods in the range of $30 \mathrm{~min}$ to $3 \mathrm{~h}$. Medium-scale TIDs (MSTIDs) have horizontal propagation velocities between $100 \mathrm{~m} / \mathrm{s}$ and $300 \mathrm{~m} / \mathrm{s}$, horizontal wavelengths of several hundreds of $\mathrm{km}$ and periods between $15 \mathrm{~min}$ and 60 min. Besides, small-scale TIDs that have wavelengths of less than $300 \mathrm{~km}$ have also been observed. They are not considered here.

According to the literature, LSTIDs are mostly associated with auroral and geomagnetic activity (e.g., Tsugawa \& Saito, 2004; Figueiredo et al., 2017, and references therein). MSTIDs are mostly associated with ionospheric coupling with the lower atmosphere, as comprehensively explained by Hunsucker (1982) and further demonstrated with experimental observations during ionosphere-troposphere coupling events such as tsunami events (e.g., Savastano et al., 2017) and convective storms (e.g., Azeem et al., 2015). Long wavelength gravity waves propagate quasi-horizontally in the thermosphere. These waves are ducted by the temperature gradient in the lower thermosphere and dominate at great distances from the source. In the mid-latitude ionosphere, these gravity waves can be observed as typical LSTIDs propagating equatorward. The second gravity wave mode, of a shorter wavelength, is a wave from the lower to the upper thermosphere that propagates near the source. In the lower atmosphere, ducted waves dominate at large distances away from the source, and Earth-reflected gravity waves propagate after reflection at the Earth's surface back into the thermosphere, where they are rapidly dissipated because of their short wavelength. However, simulation models for the generation and propagation of gravity waves, suggest a more complex mode spectrum (Balthazor \& Moffet, 1997).

Numerical simulations show that wave amplitudes are not necessarily directly related to the strength of excitation and that the source geometry is extremely important. A large enhancement of energy deposition into the ionosphere is often not accompanied by a large increase of gravity wave excitation. On the other hand, excitation of large-scale gravity waves occurs even under quiet geomagnetic conditions with relatively low energy depositions but optimal source properties (Mayr et al., 1990). These results indicate that perturbations detected in the ionospheric characteristics due to TIDs and the source of their excitation do not have a one-to-one correspondence. This is the reason why, the tracking and even the nowcasting of TIDs is very challenging.

The following requirements have to be fulfilled for the development of a comprehensive TID selection system:

Monitoring the TID drivers: TIDs constitute a specific type of space weather phenomenon that can be solar-driven or be driven by other processes acting below the ionosphere. LSTID drivers are physical characteristics that provide information on the level of solar-wind magnetosphere coupling during isolated substorms and on the impact of coronal mass ejections (CME) and corotating interaction region/solar wind high-speed streams (CIR/HSS) on the Earth environment. They are represented by the magnetosphere coupling functions, the Auroral Electrojet intensity, and the polar cap electron and proton fluxes, as summarized by Buresova et al. (2018). Recently Zhang et al. (2019), based on the analysis of GNSS differential TEC observations, suggested X-class solar flares, can be also considered to drive LSTIDs.

MSTID drivers are described by physical characteristics that specify the level of ionosphere-lower atmosphere coupling and specifically, the coupling of processes on the Earth's surface or in the lower-lying layers of the atmosphere with electric and electromagnetic phenomena in the ionosphere (Lastovicka, 2006). Upward propagating waves in the neutral atmosphere triggered by seismic activity, the occurrence of strong meteorological phenomena (large convective storms, passages of strong cold fronts, tornados, typhoons), the passage of solar terminator and solar flares are the main physical drivers of MSTIDs (Buresova et al., 2018), which in turn generates ionospheric irregularities such as spread F, N-shaped pulse disturbances or irregular variation of ionospheric parameters (Jayachandran et al., 1987; Sauli \& Boska, 2001; Xiao et al., 2007). Regarding MSTIDs, their identification and tracking contain large uncertainty, since they are associated with gravity waves propagation and plasma instability that can impact the ionospheric electrodynamics. Wide and dense networks of observing systems that include ground-based and space-borne sensors are required to monitor simultaneously disturbances in the lower atmosphere, in the ionosphere, in the magnetosphere and in the solar wind; such a network is required to draw a global picture of the solar wind - magnetosphere - ionosphere - lower atmosphere coupled system, which is necessary for monitoring of the TID drivers in real time and evaluate the criticality of the TID triggering conditions in order to issue warnings.

Detection of conditions for LSTID triggering at high latitudes: Since LSTIDs are triggered by auroral activity, it is expected that the detection of LSTIDs at high latitudes could help warning for TID activity in lower latitudes. Observational networks of Global Navigation Satellite Systems (GNSS) receivers can provide estimates of the total electron content (TEC). The perturbation in TEC at high latitudes is indicative of TID activity initiation at regions close to the gravity wave excitation source. These results can be used as an early warning for forthcoming TID activity at middle and low latitudes (Borries et al., 2017).

Development of dense networks of in situ measurements for the detection of perturbations imposed by TIDs in the bottomside ionosphere: Direct TIDs effects are primarily observed in the bottomside ionosphere (e.g., Beley et al., 1995). Specific observations must be collected from this region using dense networks of ionospheric sounders, which are able to operate in synchronised mode as transmitter-receiver pairs. These are the oblique Digisonde-to-Digisonde (D2D) "skymap" observations which were introduced by Reinisch et al. (2018). They are required to identify the disturbance in the radio wave propagation characteristics due to TIDs. Such a network exists in Europe mainly due to developments in the Net-TIDE project (Belehaki et al., 2015; Reinisch et al., 2018). This special operation mode requires continuous adjustment of the transmitting frequency to reach optimum communication conditions.

Develop methods to detect TIDs at any altitude in the bottomside and topside ionosphere: TEC parameters provide an indication of a TID without specification of the height of the maximum disturbance. Electron density reconstruction models can fulfil this need. As an example, the $3 \mathrm{D}$ version of the Topside 
Sounder Model (TSM)-assisted Digisonde (TaD) model is able to track the TID triggered disturbances in the electron density at various heights in the $\mathrm{F}$ layer and in the topside ionosphere (Kutiev et al., 2016).

Establishment of permanent networks to detect TIDs excited in the lower atmosphere: To identify TIDs triggered by mechanisms acting below the ionosphere altitudes, i.e. MSTIDs, specific methodologies are employed. These include the Continuous Doppler Sounding System (CDSS) and the GNSS detrending. The CDSS method detects MSTIDs, because of the topology of the network and its sensitivity to fast changes. CDSS networks operate in Europe and South Africa. The GNSS detrending method relies on the analysis of data from clusters of GNSS receivers to verify TID propagation characteristics with wavelength of the scales of the GNSS stations distances.

Define regional ionosphere background conditions: The amplitude of TID perturbation is directly proportional to the background electron density (Hooke, 1968). Ionospheric storms are large scale disturbances resulting in electron density enhancements or depletions depending on local time, storm time, geomagnetic location and season. Neutral winds and strong dawn-to dusk electric field can cause large uplifts or downdrafts of the ionospheric plasma leading to large-scale local time dependent enhancements or decreases of the ionospheric electron content at all latitudes. In depleted ionospheric plasma, the TIDs are faint (Reinisch et al., 2018). However, for users requesting accurate ionospheric characteristics in real time, even under ionospheric storm conditions the electron density modulation triggered by TIDs must be identifiable.

The main objective of the TechTIDE project (warning and mitigation technologies for travelling ionospheric disturbances effects) is the development of an identification and tracking system for TIDs considering all the requirements listed above. For the first time such a system operates in realtime. TechTIDE will issue the results of various detection methodologies and warnings of electron density perturbations over wide world areas. TechTIDE methodologies are based on the exploitation of data collected in real time from Digisondes, GNSS receivers, and CDSS networks.

In this paper we report on the main activities carried out in the frame of the TechTIDE project. In Section 2 we summarize the key specifications of a real-time TID warning system and the main data required to be collected and retrieved in real time; in Section 3 we present the main methodologies that are exploited in TechTIDE to detect TIDs and their detection capabilities; in Section 4 we discuss the challenges that need to be addressed for the reliable operation of a real-time TID warning system.

\section{Specifications of a real-time TID warning system and required data}

Specification of TID activity over large world regions is a key requirement from the operators of systems using or affected by ionospheric conditions; TIDs severely affect all operational systems using predictable ionospheric characteristics as they can impose disturbances with amplitudes of up to $20 \%$ of the ambient electron density, and Doppler frequency shifts of the order of $0.5 \mathrm{~Hz}$ on HF signals (Reinisch et al., 2018).
The accuracy of ground-based single-site-location (SSL) $\mathrm{HF}$ radio wave direction finding is severely compromised by the passage of TIDs through the ionospheric reflection area (Nickisch et al., 2016). Small amplitude TIDs, occurring virtually all the time with varying amplitudes, similar to cloud occurrence in the troposphere, can tilt the reflecting isodensity contours by as much as $3^{\circ}-5^{\circ}$. These time-varying tilts cause variances in the measured bearings of about $1^{\circ}$ for emitter distances of $1000 \mathrm{~km}$ to about $100^{\circ}$ for $100 \mathrm{~km}$, the "short-range catastrophe" (Ross, 1947). TIDs of larger amplitudes affect the performance of GNSS, and in particular, the Satellite Based Augmentation Systems (SBAS), such as the European Geostationary Navigation Overlay System (EGNOS, Pintor \& Roldán, 2015), as they can produce variations in TEC of several total electron content units (TECUs). These variations cannot be completely detected and corrected by these systems. This, results in a decrease of the observation accuracy and a limitation of the availability of these navigation systems for the different types of applications that they support (mainly aviation). Furthermore, it was shown by Hernández-Pajares et al. (2006) that TIDs of medium scale can affect the performance of the high accuracy navigation systems, like network real-time kinematic (N-RTK). Because N-RTK services are based on interpolating the ionospheric delays, the effect of TIDs can be quite significant. The radio astronomy community reports phase errors in low frequency radio telescope images due to small variations in TEC caused by MSTIDs (Mevius et al., 2016). Overall TIDs are a nuisance for any system using transionospheric radio wave propagation.

Basic users' requirements that need to be fulfilled by a realtime identification and tracking TIDs system, are collected by the TechTIDE consortium and summarized by Altadill et al. (2019):

- Detection of MSTIDs and LSTIDs occurrence in real time over large geographical regions.

- Estimation of the period, phase velocity, propagation direction, wavelength, and amplitude for both LSTIDs and MSTIDs.

- Estimation of the Doppler frequency, angle of arrival, and signal time-of-flight from transmitter to receiver for $\mathrm{HF}$ communications.

- Estimation of de-trended ionospheric characteristics and spectral energy contribution for specific measuring stations.

- Indication of the altitude of the maximum disturbance in the electron density over a region.

- Calculation of TEC gradients in real-time over wide regions in the globe.

- 3D electron density distribution maps over large geographical regions, for the bottomside and the topside ionosphere.

- Scaling of TID activity and characterization of the criticality of the induced disturbances in the systems concerned.

- Indication for the initiation of TIDs at high latitudes.

- Monitoring of the TID activity drivers, including the interhemispheric circulation.

- Specification of ionospheric background conditions, including the mapping of critical ionospheric characteristics foF2 and hmF2. 
To meet these requirements the TechTIDE consortium deploys several independent and complementary detection techniques which are presented in the next section. A variety of data are exploited to operate the TID detection algorithms and to calculate the indicators and monitor the drivers:

- Digisonde vertical sounding measurements and oblique Digisonde-to-Digisonde observations from the European and South African networks.

- Data from ground-based GNSS receivers.

- Data from Doppler sounders.

- Additional auxiliary data from Spacecraft missions at L1 vintage point, magnetospheric, solar and geomagnetic indices, retrieved from World and Regional Data Centers.

Digisonde vertical incidence ionospheric measurements are openly accessible through the GIRO web site. Oblique Digisonde-to-Digisonde measurements and CDSS data are owned by the TechTIDE partners: the Royal Meteorological Institute of Belgium (RMI), the Institute of Atmospheric Physics of the Czech Republic (IAP), the Leibniz Institute of Atmospheric Physics of Germany (L-IAP), the National Observatory of Athens in Greece (NOA), and the Ebro Observatory in Spain (OE). The GNSS-RINEX data files are obtained from IGS and EUREF GNSS stations and are processed in real-time by the Deutsches Zentrum für Luft- und Raumfahrt (DLR) and the Universitat Politecnica de Catalunya (UPC).

\section{TechTIDE methodologies for the real-time detection of TIDs}

In the upper atmosphere, gravity waves are observed either directly as density and velocity fluctuations of the neutral gas, or indirectly as fluctuations of the ionospheric plasma, which is in principle a passive tracer of the neutral gas motions. The ionospheric fluctuations are measured using different radio techniques employing ionosondes, HF Doppler systems, GNSS receivers, and their networks. TechTIDE warning services are based on the implementation of several methodologies that are able to detect and analyze signatures of TIDs in real time. These methodologies include the Digisonde-to-Digisonde TID detection method (HF-TID), the HF Interferometry method (HF-INT), the Doppler Sounder detection method (CDSSMSTID), the electron density perturbation at any ionospheric altitude calculated with the $\mathrm{TaD}$ ionospheric profiler model to estimate the LSTID index (LSTIDx), the Spatial and Temporal GNSS analysis that provides the MSTID index $\left(\right.$ MSTID $\left._{\text {idx }}\right)$, the GNSS TEC gradients method (TECgrad) and the Along the Arc TEC Rate (AATR) indicator method. Among them, the HF-TID and HF-INT methods are based on Digisonde observed characteristics, the CDSS-MSTID results are inferred from CDSS measurements, the LSTIDx method is based on the TaD model which combines input from ground-based Digisonde data and GNSS-TEC estimates, while other methods exploit exclusively GNSS data. The detection capabilities of the aforementioned

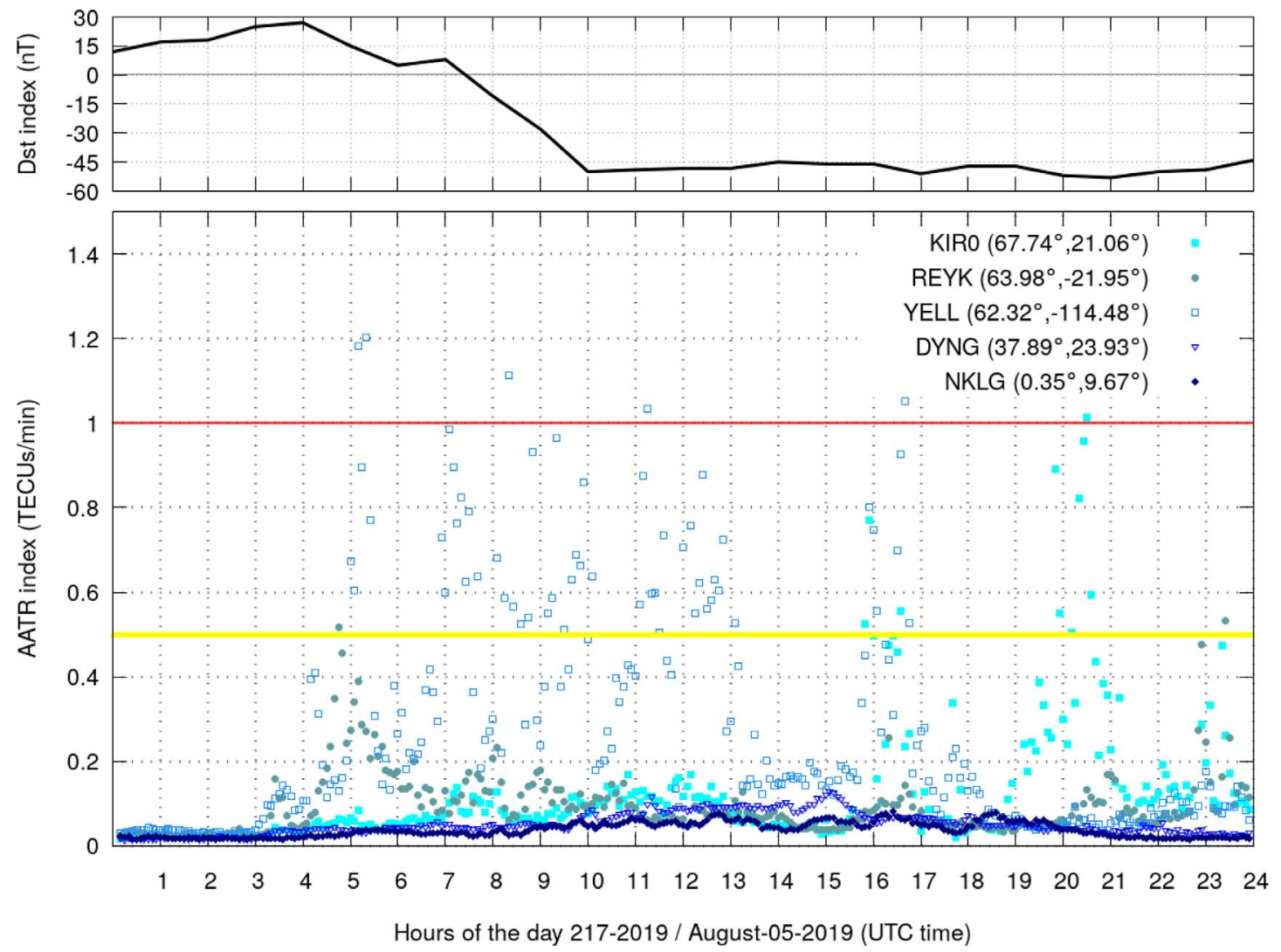

Fig. 1. Top panel: The Dst-index during 5 August 2019, the day when the initial and main phase of the moderate geomagnetic storm occurred. Bottom panel: the AATR indicator for 5 GNSS receivers at high, middle and low latitudes. 


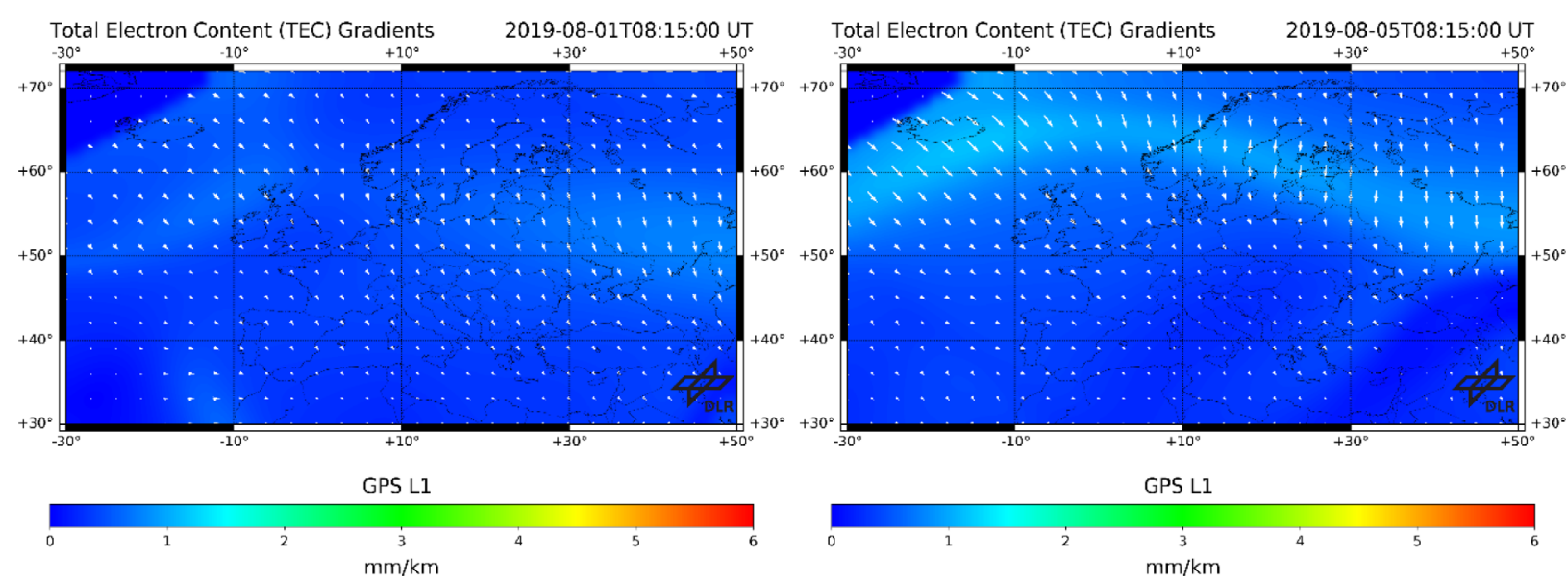

Fig. 2. Results from the gradient TEC method on the quiet day 1st August 2019 at 08:15 UT (left) and at the same time but for the disturbed day 5 August 2019 (right) when a moderate geomagnetic storm was in its main phase.

methodologies may depend on their intrinsic features but also on the configuration and the specifications of the observations' programmes. Consequently, the HF-TID, HF-INT and LSTIDx methods support the detection of LSTIDs, while the CDSSMSTID and MSTID $_{\text {idx }}$ help detection of MSTIDs. The TECgrad and AATR methods results provide indicators of TIDs occurrence as both can be interpreted as proxies of the ionospheric activity at auroral latitudes. Finally, the TechTIDE warning services are supported by the specification of the ionospheric background conditions to help the users assess the criticality of any ongoing disturbances. In the following paragraphs indicative results obtained by the TechTIDE methodologies are presented. The detection efficiency of LSTIDs is demonstrated for the period 5-9 August 2019 that is characterized by the occurrence of a geomagnetic storm of moderate intensity (min Dst $=-53 \mathrm{nT})$. The MSTID detection results are presented for a quiet day (20 January 2020) when no activity was recorded in the auroral electrojets.

\subsection{Indicators of initiation of TID activity at high latitudes}

During geomagnetic storms the high-latitude ionosphere is prone to heating and convection processes which tend to produce strong spatially and temporally variable plasma density gradients. Such gradients form the source of LSTIDs which then propagate equatorward.

The AATR indicator is a method that provides a metric for TID activity at high latitudes. The AATR indicator (Sanz et al., 2014) was developed in the context of ionospheric studies for EGNOS.

As developed in Juan et al. (2018), the AATR indicator is based on the rate of the slant TEC (STEC) variation and implements the rates of all satellites in view at a single site. The basic AATR input is the geometry-free combination of carrierphase measurements, i.e., LI $=$ L1-L2. The STEC ( $\triangle$ STEC) variation between two consecutive observations separated $\Delta t$, for a receiver $i$ and a satellite $j$, can be computed for a given epoch, $t$, as:

$$
\Delta \operatorname{STEC}_{i}^{j}(t)=\operatorname{LI}_{i}^{j}(t)-\operatorname{LI}_{i}^{j}(t-\Delta t) .
$$

The definition of the instantaneous AATR index is then given by the following equation:

$$
\operatorname{AATR}_{i}^{j}(t)=\frac{1}{(M(\epsilon))^{2}} \frac{\Delta \operatorname{STEC}_{i}^{j}(t)}{\Delta t}
$$

where, $\Delta t$ is the sampling rate of the carrier-phase measurements and $M(\epsilon)$ is an obliquity factor defined as the secant of the zenith angle at the mean ionospheric height. Finally, the RMS of the instantaneous $\operatorname{AATR}_{i}^{j}(t)$ is computed for a predefined period for all " $j$ " satellites in view from a particular station, resulting into the AATR index per a given " $i$ " receiver as:

$$
\operatorname{AATR}_{i}(T)=\sqrt{\frac{1}{N} \sum_{t=T}^{T+\Delta T} \sum_{j=1}^{n_{\text {sat }}(t)}\left(\operatorname{AATR}_{i}^{j}(t)\right)^{2}}
$$

where $N$ is total number of observations during the selected interval $\Delta T$.

Juan et al. (2018) showed that AATR can be used for specifying ionospheric activity which causes performance degradation of the EGNOS network. They established a threshold of around $0.5 \mathrm{TECUs} / \mathrm{min}$ for moderate and around 1.0 TECUs/min for large ionospheric perturbations. The TechTIDE warning system provides routinely the values of the AATR indicator at approximately 150 locations of permanent GNSS receivers worldwide in the form of a color-coded global map, as ASCII values and in daily plots that are dynamically refreshed every 5 min. Figure 1 presents the variation of the AATR indicator on 5 August 2019, during the main and recovery phase of a moderate geomagnetic storm as indicated by the Dst index variation (top panel of figure). The results from five stations are presented, REYK, KIR0, YELL in the auroral zone, DYNG at middle latitudes and NKLG at low latitudes. The yellow line is the threshold for the EGNOS system to receive warnings about moderate ionospheric disturbances, whereas the red line is the threshold for high ionospheric activity warnings. In the event shown in Figure 1, only the auroral zone stations provide AATR estimates that are higher than $0.5 \mathrm{TECU} / \mathrm{min}$, while the middle and lower latitude stations record quiet conditions. 


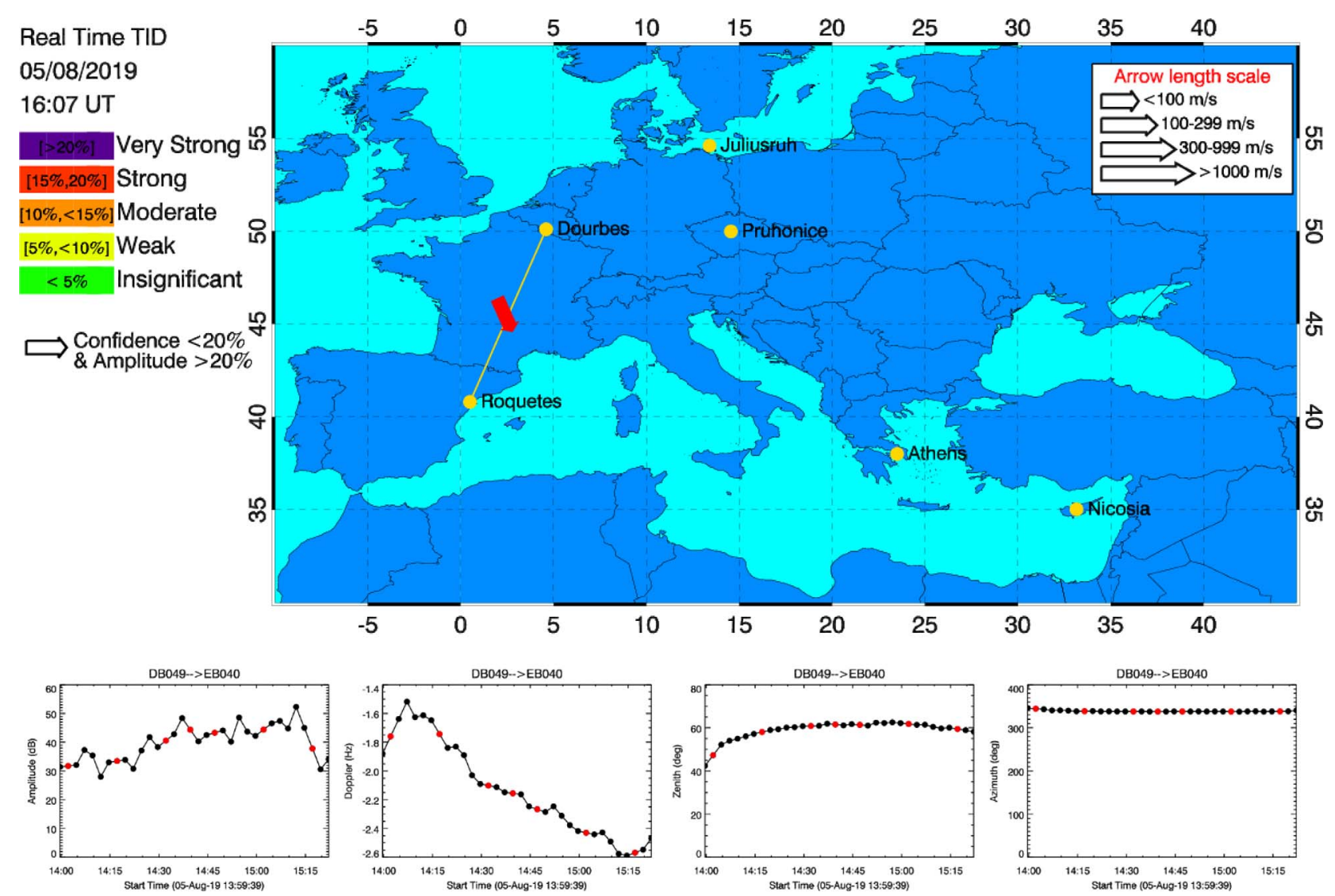

Fig. 3. Graphical representation of the HF-TID results in the TechTIDE warning system during the geomagnetic disturbed period of 5 August 2019.

The GNSS TEC gradient method has been proposed by Borries et al. (2017). The method calculates temporal and spatial TEC gradients based on TEC maps. TEC gradients are not a direct signature of TIDs. Therefore, TID occurrence cannot be directly inferred from TEC gradients. Instead, TEC gradients are considered to be precursors of LSTID activity. Significant TEC gradients at high latitudes are indicative of strong ionosphere-thermosphere perturbations, which are in turn considered to be sources of LSTIDs. Such TEC gradients are typically observed in the auroral oval. For operational purposes, the estimation of TEC gradients is based on TEC maps. Since the generation of TEC maps averages out steep TEC gradients, rather low thresholds must be assumed for the indication of the probability of LSTID generation. The statistical analysis of TEC gradients shows, that the average TEC gradient has an amplitude of about $0.2 \mathrm{~mm} / \mathrm{km}$. Alert thresholds can be based on the $90 \%, 95 \%$, and $99 \%$ quantile, derived from the complementary of the cumulative distribution function of the high-latitude region. TEC gradients are considered low with amplitudes below $1.2 \mathrm{~mm} / \mathrm{km}$, moderate with amplitudes between $1.2 \mathrm{~mm} / \mathrm{km}$ and $2 \mathrm{~mm} / \mathrm{km}$ and strong above $2 \mathrm{~mm} / \mathrm{km}$.

Figure 2 presents the results of this method derived from DLR TEC maps at $15^{\circ} \mathrm{E}$. The TEC gradient map for the geomagnetically quiet day 01 August 2019 at 08:15 UT is presented on the left side. The results for 5 August 2019, at 08:15 UT when a geomagnetic storm is in its main phase, is presented on the right. Maps of large-scale TEC gradients are routinely produced by the DLR and the results are disseminated to the users through the TechTIDE warning system.

\subsection{Large scale TID detection methodologies}

The HF-TID method (Huang et al., 2016; Reinisch et al., 2018) is based on the exploitation of DPS4D ionosonde data and is implemented to directly identify TIDs in real-time. For the real-time detection and evaluation of TIDs Digisondeto-Digisonde (D2D) data from synchronized HF sounding between pairs of DPS4D ionosondes are analysed.

The method is based on the assumption that the ionosphere is represented by a moving undulated mirror, to relate HF signal parameters to TID characteristics, using the Doppler-FrequencyAngular-Sounding (FAS) technique (Paznukhov et al., 2012). Measurement of all signal properties (Doppler frequency, angle of arrival, and time-of-flight from transmitter to receiver) proved to be instrumental in detecting the TID and deducing the TID parameters: amplitude of the detected perturbation with respect to the ambient electron density (AMP\%), propagation velocity and azimuth. The signal processing technique applied to $\mathrm{HF}$ data is capable of consistently extracting different signals that have propagated along different ionospheric paths. An intelligent system for "signal tracking" has been developed to handle the multi-path signal, based on a neural network model of 

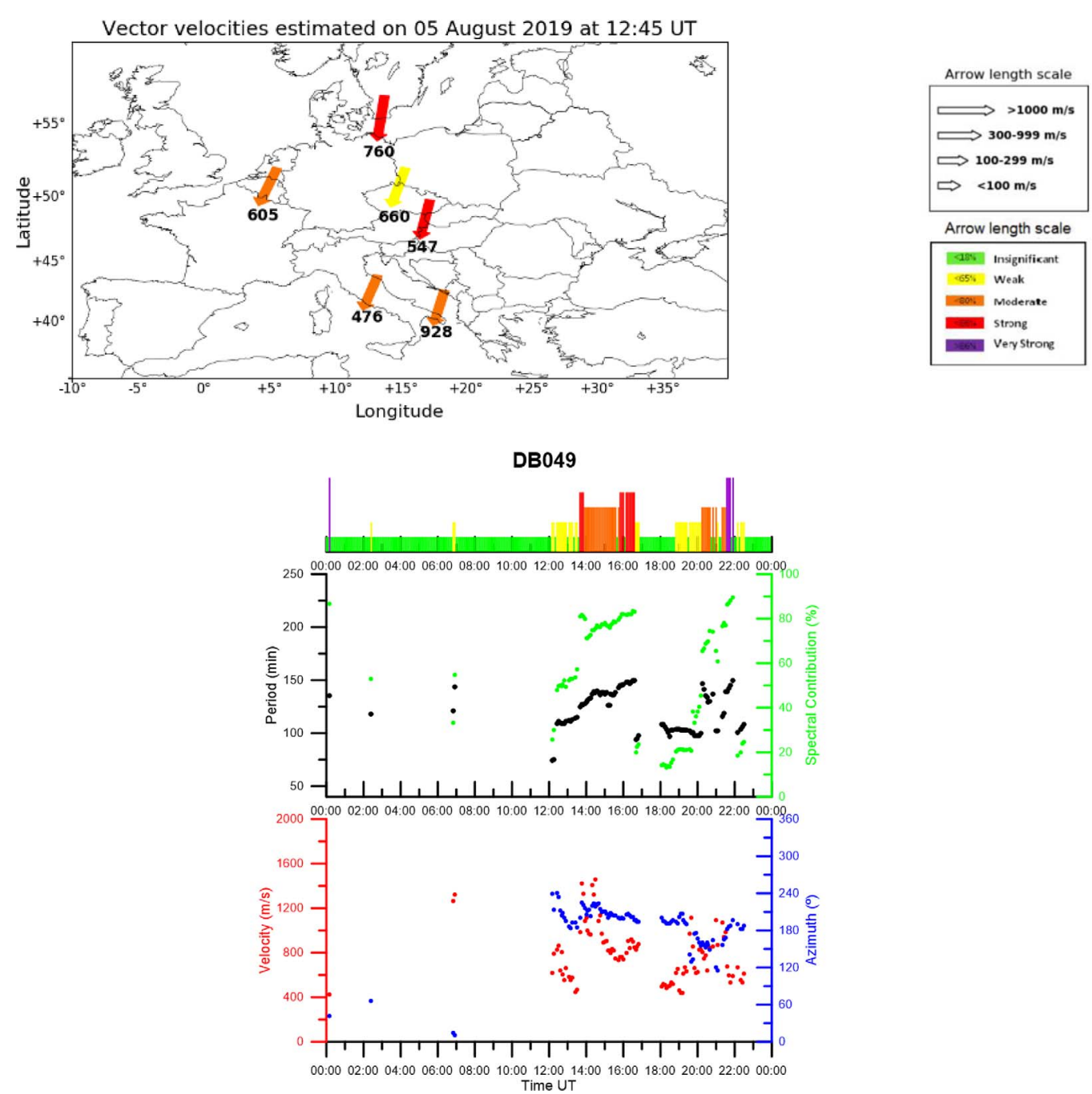

Fig. 4. Graphical representation of the HF-INT method results in the TechTIDE warning system. The European map with the TID velocities over stations are given in a colour scale which indicated the speed magnitude (top panel). Specific TID characteristics, i.e., period, spectral contribution, velocity and azimuth are presented in a daily real-time updated plot for the Dourbes Digisonde (center and bottom panels). The graphs refer to results extracted from observations collected on 5 August 2019.

a pre-attentive vision capable of extracting continuous signal tracks from the multi-path signal ensemble.

HF-TID is sensitive to the quasi-periodic variations of the $\mathrm{HF}$ radio signal recorded on oblique D2D links. Once such quasi-periodic signal behavior is detected, HF-TID uses the observed signal to infer properties of the TID wave responsible for the variation. The TID wave amplitude $A_{N}$ is one of such HF-TID derived properties, readily available for categorization and presentation to the user. While HF-TID has been proven to be sensitive even to minute undulations caused by the traveling disturbance, that determination is pertinent to a very particular area in the ionosphere. This makes estimation of the impact on the end user operations even more difficult, as these systems exhibit different sensitivity to plasma disturbances of different extent in space, both in the vertical and horizontal dimensions. Unfortunately, this means that there is no universal TID activity metric definition that would suit all systems. The perturbation amplitude $A_{N}\left(z_{0}\right)$ is an excellent candidate for a consistent and objective characterization of the TID phenomenon as evaluated by the HF-TID technique. It has a clear physical meaning and well-defined minimum and maximum values. $A_{N}$ is defined formally under assumption of a simple TID model in which, for any particular fixed altitude $z_{0}$ in the ionosphere, TID is a sinusoidal perturbation of the ambient electron density. For an easier interpretation, $A_{N}\left(z_{0}\right)$ is given in $\%$, thus ranging from 0 to $100 \%$. The HF-TID version presented here defines five levels of LSTID activity in relation to the detected amplitude; Insignificant activity for events with AMP $<5 \%$, weak for events with $5 \% \leq \mathrm{AMP}<10 \%$, moderate for events with $10 \% \leq$ AMP $<15 \%$, strong for events with $15 \% \leq$ AMP $<20 \%$, and very strong activity for events with $\mathrm{AMP} \geq 20 \%$.

The performance of the method has been demonstrated with oblique D2D "skymap" observations from European Digisondes (Reinisch et al., 2018). The method can detect 

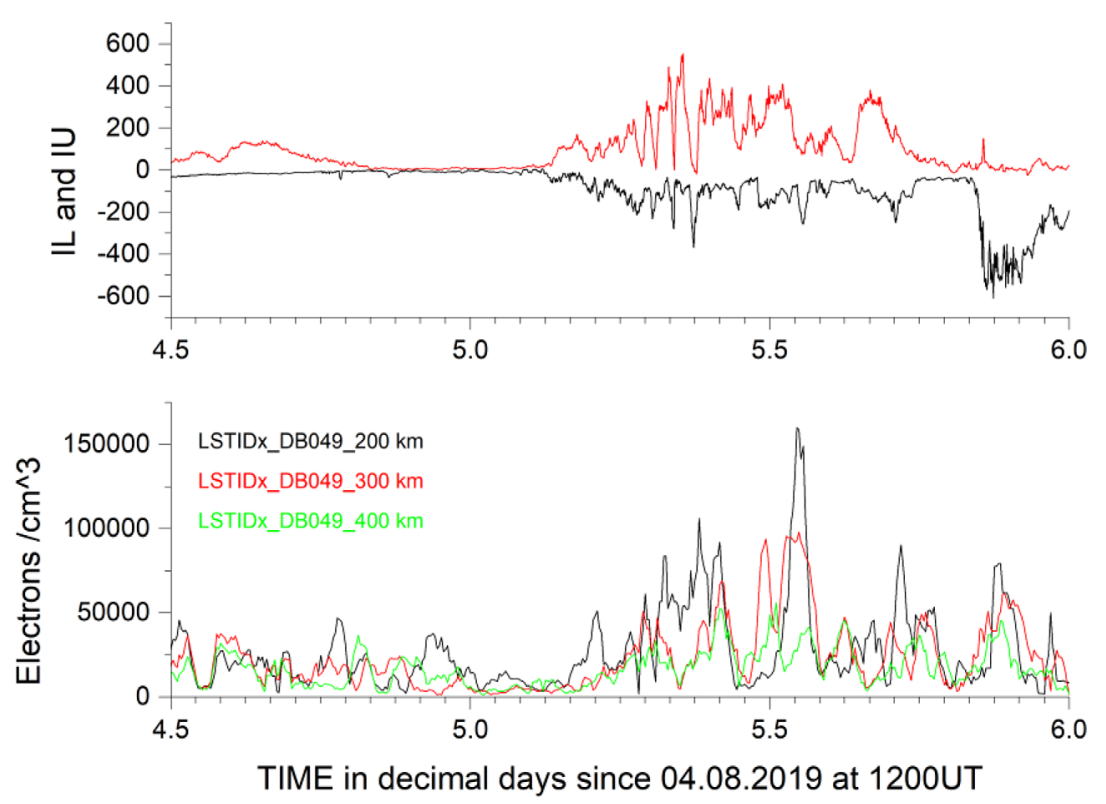

Fig. 5. Bottom panel: The LSTIDx calculated with the TaD model for three heights at $200 \mathrm{~km}, 300 \mathrm{~km}$ and $400 \mathrm{~km}$, during the moderate geomagnetic storm on 5 August 2019. The TaD model results are calculated using data from Dourbes Digisonde (DB049). Top panel: The auroral electrojet indices IU and IL provided by the IMAGE magnetometer network in Finland.

electron density perturbations from $5 \%$ to $20 \%$ of the ambient electron density making possible the identification of both LSTIDs and MSTIDs. The method is implemented in real time in TechTIDE and provides the signatures of TID activity detected by any active pair of Digisondes performing D2D measurements in bistatic link mode. For the 5 August 2019 storm, only the link between the Ebro (EB040, Rx) and Dourbes (DB049, Tx) Digisondes was operated systematically. Figure 3 presents the map at 16:07 UT with the TID propagation direction and the visualization of the amplitude, Doppler, zenith, and azimuth of the detected TID.

The HF-Interferometry (HF-INT) method identifies LSTIDs for the monostatic measurements of a given network of HF sensors (i.e. ionosondes). The spatial distribution of the network should be dense enough to detect LSTID i.e., distance between measuring sites no larger than $1000 \mathrm{~km}$. The method detects quasi-periodic oscillations of ionospheric characteristics, identifies coherent oscillation activity at different measuring sites of the network and sets bounds on time intervals for which such activity occurs in a given region. The disturbance potentially associated to TID in the last 6-h interval can be related to the de-trended ionospheric characteristics after removing the main daily harmonics. The dominant period of oscillation and amplitude of the LSTID are obtained by spectral analysis. This allows for identification of TID activity from Digisonde networks. The vector velocity of propagation is estimated by the measured time delays of the disturbance of a given ionospheric characteristic at different sensor sites and assuming a plane wave propagation. Classification of the TID activity for the HF-INT method is related to the spectral energy contribution (SEC) of the detected TID. Altadill et al. (2019, 2020a) have shown that the SEC of a given LSTID to the total spectral energy is equivalent to the contribution of the LSTIDs to the total variability for a given time series. Thus, the larger the SEC of a LSTID, the larger the impact of the LSTID to the variability. Altadill et al. (2020b) have performed a statistical analysis for all events detected during 2018 in the European region. As a result, they have defined different levels of activity from the distribution of the cumulative number of events for a given SEC or lower (Fig. 4 in Altadill et al., 2020b). The first decile of the distribution defines the threshold between Insignificant and Weak activity. The second quartile of the distribution defines the threshold between weak and moderate. The third quartile defines the threshold between moderate and strong, and the ninth decile defines the threshold between strong and very strong activity. Thus, we define Insignificant activity for events with SEC $<18 \%$, weak for events with $18 \% \leq$ SEC $<65 \%$, moderate for events with $65 \% \leq$ SEC $<80 \%$, strong for events with $80 \% \leq$ SEC $<86 \%$, and very strong activity for events with $\mathrm{SEC} \geq 86$.

In TechTIDE, the method is implemented in real time based on typical ionospheric characteristics measured with Digisondes in the European and South African Digisonde Networks (Altadill et al., 2020a). Representative products released by TechTIDE for the disturbed day 5 August 2019, based on the HF INT method are shown in Figure 4. LSTID activity is detected after 12:00 UT in the lower panel with the method's characteristics variation over Dourbes Digisonde during that day. The European map which corresponds to 12:45 UT shows coherent activity at all locations providing data at that specific time.

The TID-induced perturbations in electron density predicted with the TaD model. The Topside Sounder Model (TSM)-assisted Digisonde (TaD) profiler provides vertical electron density profiles (EDP) above Digisonde sounding stations operating in Europe, from the bottom of the ionosphere up to the GNSS orbit altitude (Kutiev et al., 2016). This model is based on the Topside Sounder Model (TSM) proposed by Kutiev et al. (2006). The TSM model provides with empirical 
A. Belehaki et al.: J. Space Weather Space Clim. 2020, 10, 42

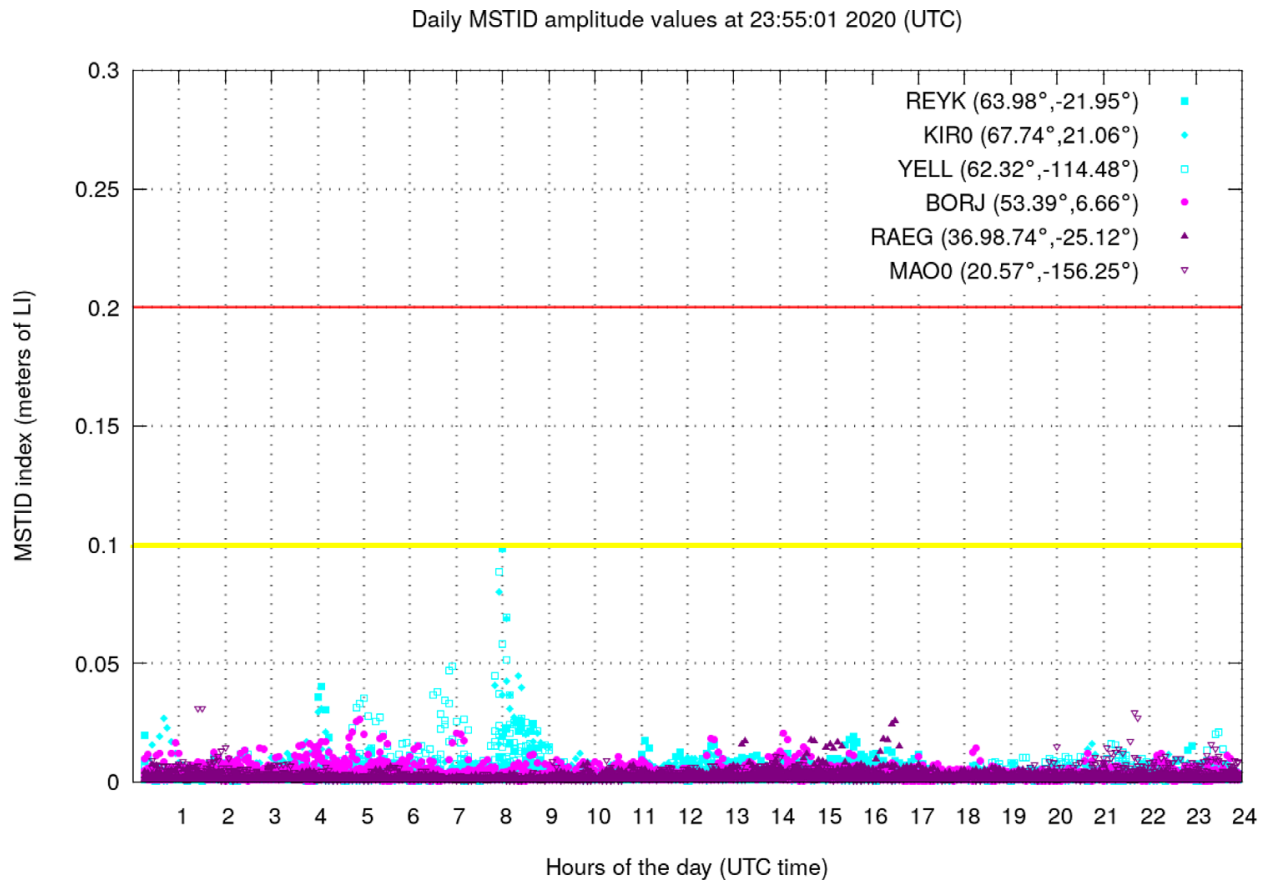

Fig. 6. The daily plot for the MSTID index for 20 January 2020, with the results from six GNSS receivers at high, middle and low latitudes, as indicated in the color coded legend.

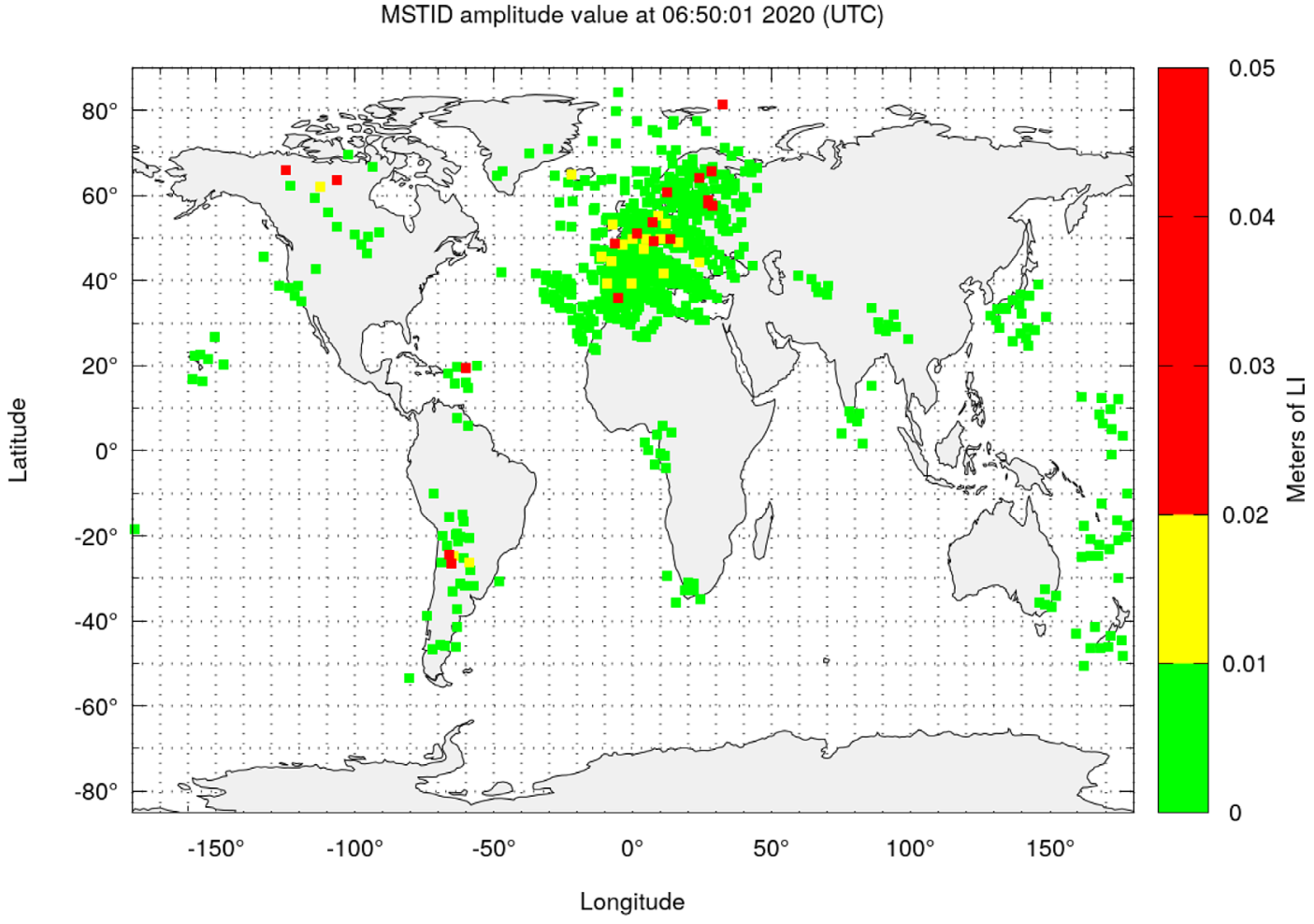

Fig. 7. The global map of the MSTID activity index at 06:40 UT on 20 January 2020. 


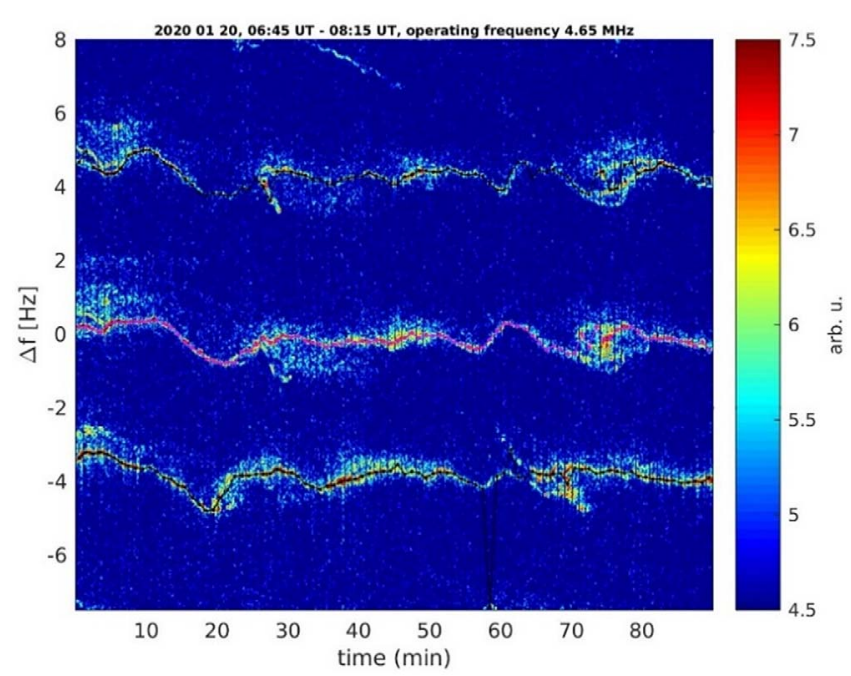

Fig. 8. The CDSS system which is located in Czech Republic detected significant activity on 20 January 2020 in the morning sector simultaneously with the intensification of MSTID index in Europe shown in Figure 6.

equations the scale height and transition height in the topside ionosphere from the Alouette/ISIS topside sounders data. The results are updated for the actual ionospheric and geospace conditions with the ionospheric characteristics at hmF2 (the critical frequency foF2, the true height $\mathrm{hmF} 2$ and scale height $\mathrm{Hm}$ of the F2 layer) obtained from an ionospheric sounder and with the TEC parameter at the location of the ionospheric sounder.

The electron density predicted by the model at various heights is detrended with 1-h running averages. At each different height, the LSTID index (LSTIDx) is derived as the absolute values of the residuals of the current detrended values from the 30-days running median detrended values. For this methodology to be effective, the time resolution of the source vertical sounding ionospheric parameters must be at least $5 \mathrm{~min}$. Some representative LSTIDx results are shown in Figure 5 for three heights at $200 \mathrm{~km}, 300 \mathrm{~km}$ and $400 \mathrm{~km}$, during the moderate geomagnetic storm of 5 August 2019. The results are calculated using Digisonde data from the Dourbes ionospheric station. The auroral electrojet indicators IU and IL provided by the IMAGE magnetometer network in Finland are presented in the top panel of Figure 5, to give a measure of the auroral activity in the European longitude sector. The strongest values of the LSTIDx are detected at $200 \mathrm{~km}$. LSTIDx decreases quickly towards higher altitudes. At $400 \mathrm{~km}$ the perturbation marginally exceeds the background levels. These results are in agreement with earlier studies reporting that TID amplitudes maximize near or below the background electron density maximum hmF2 (e.g., Morgan \& Ballard, 1978).

In the current version of the TechTIDE warning system the LSTIDx is computed with autoscaled data. The autoscaled data include very often outliers and gaps. The large number of outliers produces noise in any statistical analysis attempted to define activity levels. Unless an intelligent method is applied to overcome this issue, the LSTIDx must be evaluated in correlation with a relevant driver, which for the middle European latitudes, is the IL and IU indicator from the IMAGE magnetometer network, as shown in the case presented in Figure 5.

\subsection{Medium scale TID detection methodologies}

The detection of MSTIDs is based on data collected from ground-based GNSS receivers and from Continuous Doppler Sounding Systems.

The Spatial and Temporal GNSS analysis procedure detects and characterises TIDs, including velocity and period, based on GNSS measurements (Hernández-Pajares et al., 2006). This procedure allows the study of any ionospheric perturbation and can be used for detecting a TID (with a single receiver) and estimating the propagation parameters (from a network of receivers). The basic GNSS measurement used is the geometry-free combination of carrier phases, with measurement noise at the level of few millimetres. The first step for the TID detection is to detrend the data in order to remove the wellknown dependences, such as diurnal and elevation angle variations, which have larger time scales than the TID. This detrending can be applied in realtime and for a single receiver to calculate the MSTID index $\left(\mathrm{MSTID}_{\mathrm{idx}}\right)$ for each transmitterreceiver pair or for a RTK network. Therefore, information about the TID occurrence can be obtained for the monitored region around the receiver. In the case of small networks, as it is shown in Hernández-Pajares et al. (2006), it is possible to estimate the MSTIDs propagation parameters (velocity and direction) from the differential effects experienced by different receivers on the network.

Users with a single frequency receiver can achieve confidence on their positioning solution by using just observations with MSTID $_{\text {idx }}<0.01$ LI meters (LI is the geometry free combination of carrier phases, i.e. $\mathrm{LI}=\mathrm{L} 1-\mathrm{L} 2)$. $\mathrm{MSTID}_{\mathrm{idx}}$ is a representative index for ionospheric perturbations with time scales from some minutes to tens of minutes, which are the typical periods of MSTIDs. According to its definition, MSTID idx $_{\text {var- }}$ ies largely depending on the receiver location. To specify this effect, a statistical study was performed with MSTID $_{\text {idx }}$ results for the years 2018 and 2019, for a receiver at high latitude (KIRU) and a receiver at mid latitude (EBRE), using the complementary of the cumulative distribution function (1-CDF), i.e. the probability of being the MSTID $_{\text {idx }}$ larger than a specific value. The results indicate that the activity at high latitude is much more pronounced than at mid latitude, with the highlatitude MSTID $_{\text {idx }}$ larger than 0.01 LI meters in around $10 \%$ of the cases. On the other hand, ionospheric activity at these time scales is, in general, very low at mid latitude. However, the N-RTK service, with single frequency receivers, requires high accuracy in the ionospheric corrections, thus it can be affected by perturbations with only some tenths of a TECU of amplitude. In this sense, observations with $\mathrm{MSTID}_{\mathrm{idx}}>0.01$ LI meters (i.e. around 0.1 TECUs) cause a non-negligible positioning error.

An example of the MSTID $_{\text {idx }}$ as presented in the TechTIDE warning system is shown in Figure 6 . Here, the daily plot for 20 January 2020 is presented, with the results from six GNSS receivers at high, middle and low latitudes, as indicated in the color 
coded legend. Figure 7 shows the global map the same day at 06:40 UT.

The CDSS-MSTID detection method is based on the analysis of multipoint CDSS operating at three frequencies $(f=3.59,4.65$, and $7.04 \mathrm{MHz})$ in the Czech Republic, at $3.59 \mathrm{MHz}$ in South Africa, at $4.63 \mathrm{MHz}$ in Northern Argentina and at $4.66 \mathrm{MHz}$ in Taiwan. There are at least three sounding paths (transmitter - receiver pairs) at each frequency at each location. The CDSS method is suitable for the monitoring of MSTIDs but not of LSTIDs. There are two reasons. First, the triangle of measuring points has a horizontal expansion of the order of $100 \mathrm{~km}$, which is suitable for the monitoring of MSTIDs. Second, temporal changes at LSTIDs are slower, i.e. CDSS is less sensitive to them.

The basic principles of the Doppler sounding and phenomena that can be analysed were reviewed by Lastovicka \& Chum (2017). For the automatic detection and analysis of MSTIDs in real-time only CDSS operating at $4.65 \mathrm{MHz}$ in the Czech Republic is used.

The recorded data are automatically processed in several steps. The complete computation is repeated every $15 \mathrm{~min}$. First, Doppler shift spectrograms are computed for the last 90-min record (e.g., Fig. 8). Then maxima of spectral intensities are searched in three frequency bands that correspond to the frequency bands of signals from the individual transmitter to receiver pairs. The frequencies $f_{D i}$ corresponding to the maxima of spectral intensities for each transmitter-receiver pair are stored together with powers $p_{p i}$ calculated in the narrow frequency band around these maxima (bandwidth on the order of $\sim 0.1 \mathrm{~Hz}$ ). In addition, powers $p_{T i}$ in the whole frequency bands in which the maxima are searched are evaluated (frequency band of about $4 \mathrm{~Hz}$ ). In addition to the values of $f_{D i}$ and $p_{p i}$ the power ratios $r_{i}=p_{p i} / p_{T i}$ are also stored to a file with 1-min step (the stored values are $1 \mathrm{~min}$ averages). High values of $r_{i}$ approaching 1 indicate clear signals suitable for further analysis, whereas low values of $r_{i}$ indicate signals with insignificant spectral maxima that occur e.g. under spread F conditions. Such signals are inconvenient for further analysis.

In the next step, the stored values of $f_{D i}, p_{p i}$ and $r_{i}$ are analyzed. First, the offsets are removed to obtain $f_{D C i}=f_{D i}-\left\langle f_{D i}\right\rangle$ where $\left\langle f_{D i}\right\rangle$ is the mean value calculated over the 90-min intervals. Next the validity of criterion (1) is tested,

$$
\left(p_{p i}>\mathrm{Th}_{1}\right) \quad \text { and } \quad\left(r_{i} \geq \mathrm{Th}_{2}\right)
$$

The requirement $\left(p_{p i}>\mathrm{Th}_{1}\right)$ ensures that sufficient signal power was received ( $\mathrm{Th}_{1}$ is an experimentally found threshold). Insufficient power is received, e.g., if the critical frequency is lower than sounding frequency $f=4.65 \mathrm{MHz}$ and the signals do not reflect from the ionosphere. The second requirement $\left(r_{i}>\mathrm{Th}_{2} ; \mathrm{Th}_{2} \sim 0.5\right)$ ensures that the spectral maxima are significant (e.g., no spread F occurred). TIDs are only analyzed if condition (1) is fulfilled for more than $80 \%$ of data points in the last $90 \mathrm{~min}$. The observed horizontal velocity and azimuth of propagation are then computed from the observed time (phase) delays between signals recorded for different sounding paths (transmitter-receiver pairs) using three different calculation methods described by Chum \& Podolská (2018): (i) slowness search; (ii) least squares fitting to the time delays obtained from cross-correlation of the $f_{D C i}$ series; (iii) weighted least squares fitting to the time delays obtained from cross-correlation of the $f_{D C i}$ series; the weights are the maxima of the crosscorrelation functions. The values of $v_{H}$ and azimuth $\mathrm{AZ}$ that are finally reported are the mean values of $v_{H}$ and $\mathrm{AZ}$ quantities obtained by the three different methods; their uncertainties are estimated as corresponding standard deviations. Specifically, 2-D versions of the described methods are used. In addition, root mean square (RMS) value of Doppler shift and dominant periods are evaluated. It should also be noted that the $f_{D C i}$ series are first filtered to keep only signals with periods from 4 to $50 \mathrm{~min}$. The aim is to remove a possible high frequency noise and to remove long-period fluctuations (large-scale TIDs) that cannot be reliably analyzed with respect to 90 -min intervals and with respect to the relatively small spatial scale (tens of $\mathrm{km}$ ) of the measuring array defined by the reflection points.

Figure 8 shows the Doppler shift spectrogram recorded in Czech Republic on 20 January 2020 from 06:45 UT to 08:15 UT at the operating frequency $4.65 \mathrm{MHz}$. Figure 8 also demonstrates an example of a relatively complex Doppler shift spectrogram with ambiguous spectral peaks during several subintervals (e.g., around 75 min elapsed time) and an outlier in the automatic determination of a spectral peak in the bottom trace (around $60 \mathrm{~min}$ elapsed time). The results of automatic MSTID propagation analysis for the time interval in Figure 8 are as follows: observed horizontal velocity $v_{\mathrm{obs}} \sim 230 \mathrm{~m} / \mathrm{s}$, azimuth $\mathrm{AZ} \sim 200^{\circ}$; the results after manual corrections are: $v_{\text {obs }} \sim 190 \mathrm{~m} / \mathrm{s}, \mathrm{AZ} \sim 135^{\circ}$. The RMS value of Doppler shift is about $0.25 \mathrm{~Hz}$. Within the same period, the MSTID shows an intensification in the stations located in central Europe as seen in the map presented in Figure 7. The auroral electrojets during that day were extremely weak, as documented by the $\mathrm{AE}$ indices (not shown here), and this is an indication that the disturbances seen with the two methods do not have a magnetospheric origin and must be related to other drivers, which probably are disturbances in the lower atmosphere. Moreover, the propagation analysis of MSTIDs by CDSS often shows roughly poleward propagation, especially during the summer season (Lastovicka \& Chum, 2017; Chum \& Podolská, 2018, and references therein).

The characterization of the TID activity scales based on the CDSS Doppler shift is under continuous development as new results are accumulated in the TechTIDE database.

\subsection{Specification of ionospheric background conditions}

Ionospheric background conditions provide the first indication to the user about the overall disturbances in the ionosphere over a region of interest and about the probability for TID detection given that for TIDs produced by gravity waves, the amplitude of the TID perturbation is directly proportional to the background electron density (Hooke, 1968). Ionospheric background conditions are defined by the normal ionospheric variability and by large scale ionospheric storm effects. The key characteristic among the ionospheric conditions is the electron density. To obtain the electron density distribution in the bottomside and topside ionosphere over an extended region such as Europe, we apply the $3 \mathrm{D}$ version of the TaD model. The 3D 

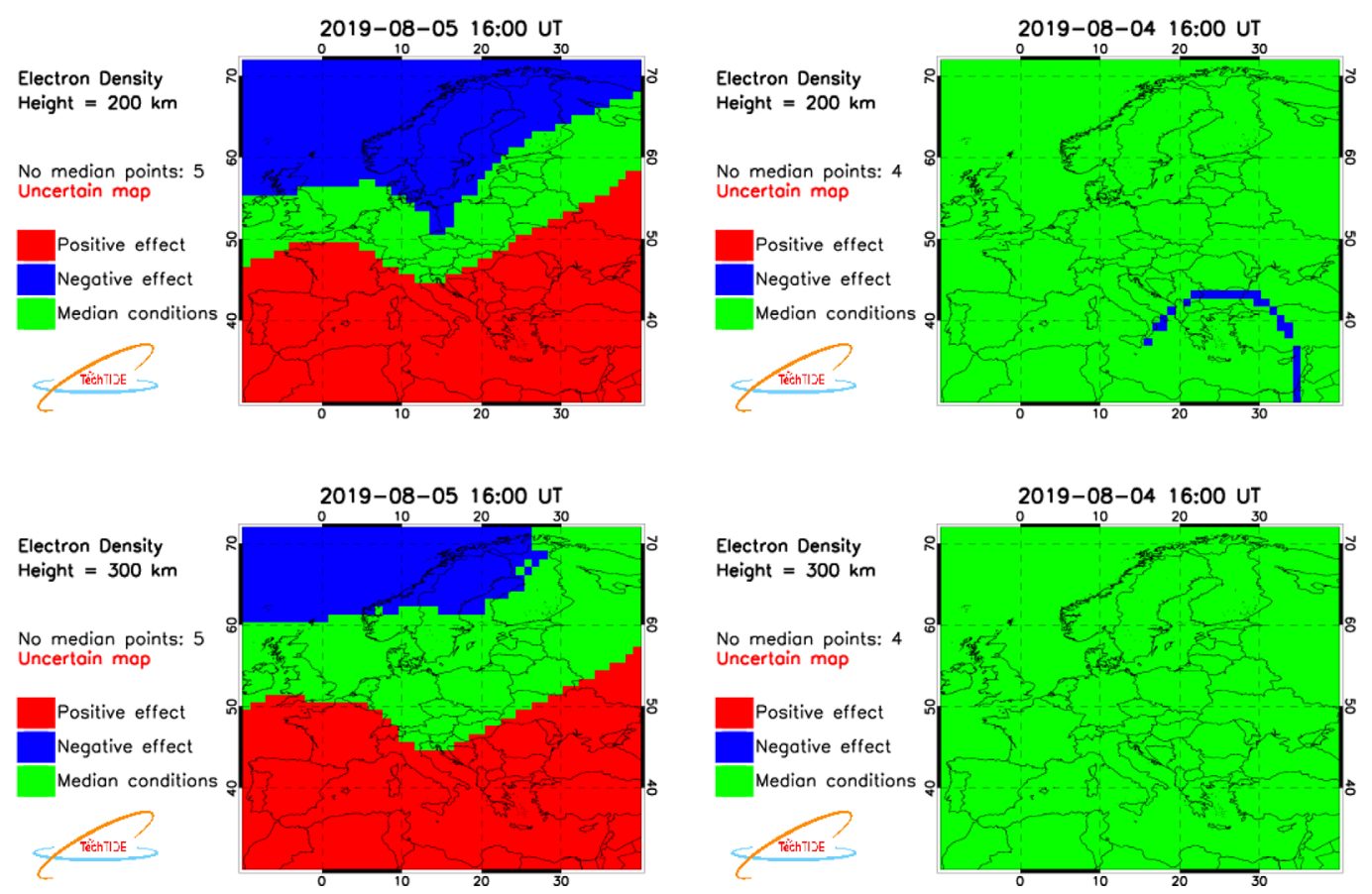

Fig. 9. Ionospheric background activity maps calculated during the main phase of a moderate storm (left) and during a quiet day (right), using the relative standard deviation of the electron density at each ionospheric altitude, taken into account for the estimation of the median values. Here the maps at $200 \mathrm{~km}$ (top row) and at $300 \mathrm{~km}$ (bottom row) are presented.

mapping technique is described in Kutiev et al. (2016). The $\mathrm{TaD}$ profiler first computes electron density profiles (EDP) over the European Digisonde locations. For the implementation of the method in TechTIDE, ionospheric data of foF2 and hmF2 are used from the European Digisondes of Athens, Rome, Ebro, Dourbes, Pruhonice, Juliusruh and Chilton. Using the Polyweight interpolation method the $2 \mathrm{D}$ maps of the basic ionospheric plasma parameters at the height of maximum electron density concentration, are derived. The TaD profiler calculates EDPs at each node and adjusts them to the GNSS-TEC values extracted from the GNSS TEC maps (Belehaki et al., 2012; Kutiev et al., 2012). Electron density at any arbitrary point within the 3D space is calculated by a linear interpolation from their respective values at the neighbouring grid nodes. The electron density distribution (EDD) between any two points in the space is then obtained by calculating successive ED values with a defined step along the ray path. The model error based on the comparison of 3D EDD model values with vertical TEC (vTEC) and slant TEC (STEC), calculated from individual GNSS receivers, is $10 \%$ for STEC and 6\% for vTEC (Kutiev et al., 2016). Belehaki et al. (2017) showed the sensitivity of the TaD EDD to disturbances in the electron density due to LSTIDs and the model capability to detect the altitude of the maximum perturbation.

In TechTIDE, the 3D electron-density maps $\mathrm{Ne}(i, j, k)$ (where $i$ denotes the latitude, $j$ the longitude and $k$ the height) produced by the $\mathrm{TaD}$ model are used for the derivation of the near-real time ionospheric condition maps in Europe for the heights of 200,300,400, and $500 \mathrm{~km}$. The respective median $\operatorname{MED}(i, j, k)$ and the standard deviation $\operatorname{STD}(i, j, k)$ maps are produced using the electron density maps corresponding to the same UT over the previous 30 days and two quantities $a$, $b$ are derived as follows:

$$
\begin{gathered}
a(i, j, k)=100 \times \frac{[\operatorname{Ne}(i, j, k)-\operatorname{MED}(i, j, k)]}{\operatorname{MED}(i, j, k)} \\
b(i, j, k)=100 \times \frac{\operatorname{STD}(i, j, k)}{\operatorname{MED}(i, j, k)} .
\end{gathered}
$$

In practice, the STD map reflects the standard deviations of the values taken into account in the calculation of the corresponding medians at each point of the grid. In this respect, $b$ that represents the relative STD (\%) aims to delimit the normal ionospheric variability (Tsagouri et al., 2018b, 2018c). Ionospheric effects at each pixel of the map $(i, j, k)$ are characterised as "median" when $|a| \leq|b|$, as "positive" when $|a|>|b|$ and $a>0$ and as "negative" when $|a|>|b|$ and $a<0$. A map is considered as "uncertain" if less than 17 maps are used for the derivation of the median and standard deviation maps. When a specific effect characterizes more than $80 \%$ of the ionospheric effect map then this effect is considered as dominating, otherwise if the sum of pixels with positive and negative effects exceeds the number of pixels with median effects, conditions tend to be disturbed while conditions tend to be median in the reverse case. Note that the area covered by Digisonde observations is delimited in latitude and longitude by the four stations at its edges, Chilton, Ebro, Athens, and Juliusruh. This area includes the $80 \%$ of the mapped region. That is why the $80 \%$ percentage is critical to characterize conditions over Europe. 
Table 1. TechTIDE detection methodologies for TIDs.

Detection method and main characteristics
Methods specific to the detection of LSTIDs
HF-TID
Input: Signal properties from Digisonde synchronized operation.
Output: TID velocity, amplitude, propagation direction at the
signal reflection point between the stations.
The method is fully described in the paper by

Reinisch et al. (2018).

\section{HF interferometry}

Input: Ionospheric characteristics from VI and OI soundings.

Output: 2D TID vector velocity, amplitude, period and spectral energy contribution.

The method is described in the paper by Altadill et al. (2020a) while the calculation of the corresponding activity levels is given in the TechTIDE project report by

Altadill et al. (2020b).

\section{$1 D$ version of TaD-EDD model - LSTID index}

Input: Ionospheric characteristics at the hmF2 altitude and TEC maps.

Output: Analytical function of the electron density distribution with altitude from $90 \mathrm{~km}$ to $22,000 \mathrm{~km}$.

The method is first proposed by Belehaki et al. (2017).

\section{Methods specific to the detection of MSTIDs \\ CDSS-MSTID}

Input: CDSS reflected signals, ionospheric characteristics and irregularities.

Output: Doppler shift, Doppler shift. Fluctuations associated to the TIDs and estimation of the propagation parameters (direction, velocity, and amplitude).

The method is fully described in the paper by Chum \& Podolská (2018).

\section{Spatial \& temporal GNSS analysis}

Input: GNSS TEC from single receivers over a region.

Output: Fluctuations associated to the TIDs and estimation of the propagation parameters (direction, velocity, and amplitude).

The method is first proposed by Hernández-Pajares et al. (2006).

\section{Indicators}

\section{GNSS TEC gradient}

Input: Grids of TEC maps over a region.

Output: Latitude-time maps of TEC gradients and indication of significant gradients.

The method is described in the paper by Borries et al. (2017).

\section{AATR indicator}

Input: Slant TEC parameters.

Output: The along Arc STEC Rate, metric to characterize the ionosphere operational conditions of EGNOS.

The method is described in the paper by Juan et al. (2018).

\section{Ionospheric background conditions}

Input: Ionogram derived characteristics in the F2 layer from ionosondes; GNSS TEC at the ionosonde location; geomagnetic, and solar flux indices.

Output: Maps of the electron density at any height in the bottomside and topside ionosphere.

The methodologies that define ionospheric background conditions are described in the TechTIDE project report by Tsagouri et al. (2018a).
Products

1. European map indicating the velocity, amplitude and propagation direction at the reflection points between Digisondes operated in bistatic mode.

2. Report of TID characteristics extracted from the analysis of the raw data from the D2D operations, i.e TID propagation Doppler frequency, angle of arrival, and time-of-flight from Tx to Rx, both OI and VI sounding.

3. Plots of amplitude, Doppler, azimuth within the last $45 \mathrm{~min}$ from the TID detection.

Dominant period, amplitude and horizontal vector velocity of detected LSTID over the region of interest and over each Digisonde location.

LSTID index: The residuals of the detrended electron density from the median values, calculated with the $\mathrm{TaD}$ model for heights ranging from 150 up to $900 \mathrm{~km}$ with $50 \mathrm{~km}$ step. The results are provided over specific European Digisondes performing VI sounding at least every $5 \mathrm{~min}$.

Period, amplitude of Doppler measurements, observed horizontal velocities and azimuths of MSTIDs.

MSTID index calculated at each GNSS contributing receiver.

Maps of TEC gradients for the European region

Along Arc TEC Rate (AATR) calculated at each contributing GNSS receiver.

Maps of relative standard deviation of the electron density at each ionospheric altitude with an indication of the probability for LSTIDs detection. 


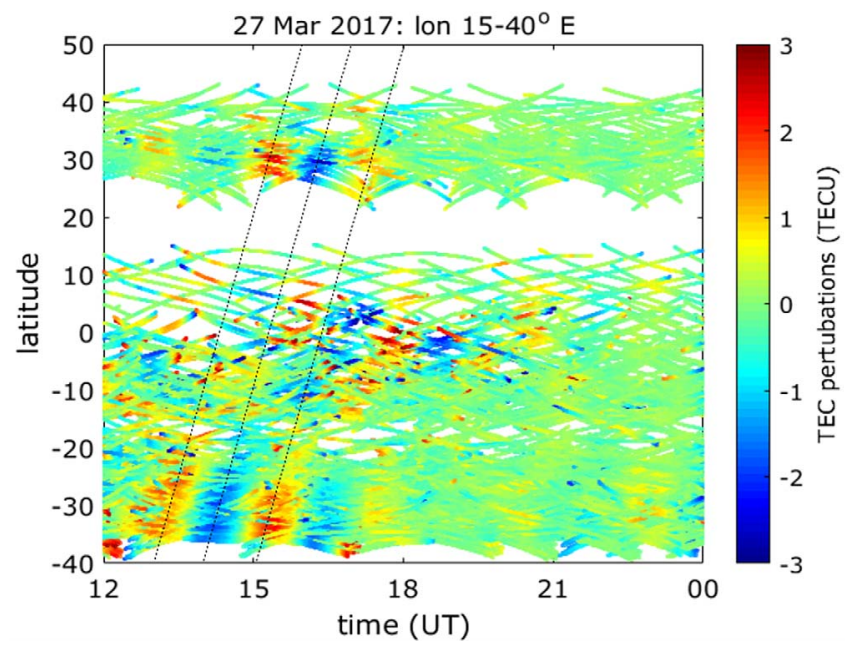

Fig. 10. Northward propagating LSTID (dotted lines) starting in the southern hemisphere, crossing the equator and propagating into the northern hemisphere. Shown is the difference between observed TEC and an unperturbed TEC background. Latitude is geographic. The geomagnetic equator is located about $10^{\circ}$ north of the geographic equator. Figure kindly provided by Zama Katamzi-Joseph, South African National Space Agency.

Table 2. Interhemispheric characteristics of LSTID observed during geomagnetic storms. The total number of events analysed is 26 . The first three-row group shows the distribution according to the LSTID geographic origin, the second according to interhemispheric appearance. Each group sums up to 26 .

LSTID observed during geomagnetic storm periods 26

LSTID of high latitude origin propagating equatorward

LSTID of equatorial origin propagating poleward

LSTID of both high latitude and equatorial origin

LSTID observed in both hemispheres without

interhemispheric circulation

LSTID with observed interhemispheric circulation

No conclusive results due to insufficient data in one hemisphere

The time resolution of the maps is 15 min which is required to monitor the evolution of large-scale disturbances. An example is shown in Figure 9 for a disturbed day (left) and for the day before which is a quiet day (right). The disturbed day is the 5th August 2019 and at the selected timestamp 16:00 UT the main phase of the geomagnetic storm is ongoing. These maps indicate conditions favorable for TID identification since the sum of pixels with positive and negative effects exceeds the number of pixels with median effects. The maps for the day before, show clearly that quiet conditions dominate in the selected ionospheric heights.

\section{Discussion}

TIDs are propagating waves altering an a priori variable ambient ionospheric electron density distribution. The TechTIDE project provides for the first time a real-time identification and tracking system for TIDs. The TechTIDE warning system provides the results of complementary TID detection methodologies and many potential drivers to help the users assess the risks and develop mitigation strategies tailored to their applications.

The TID detection methodologies deployed in the TechTIDE project rely on data retrieved from ionosonde and GNSS observations. Both types of observations have advantages and disadvantages with respect to TID detection capabilities. The known disadvantage of the TEC measurements is the integration of the electron density over the entire satellite-ground signal path. Considering that the most significant contribution to the TEC value comes from the topside ionosphere (e.g., Belehaki $\&$ Tsagouri, 2002), there are concerns about the sensitivity of the GNSS TEC measurements to the smaller scale ionospheric disturbances which may not affect the entire volume of the ionosphere. Data obtained from HF sounding can have higher sensitivity to smaller scale disturbances since the HF waves are reflected in the lower part of the ionosphere at the heights where the local plasma gyrofrequency is equal to the sounding frequency. On the other hand, certain gaps exist in the data which are associated with small signal-to-noise ratios and signal degradation through electromagnetic interference and sporadic $\mathrm{E}$ layers. They are most frequent at middle latitudes where TIDs also occur. The opportunity and challenge for the TechTIDE research community is to demonstrate that combined analysis of results from different TID detection methodologies based either on HF soundings or GNSS TEC data or on both can lead to improvements in the calculation of TID characteristics confidence levels, for both medium and large scale TIDs, under various different geophysical conditions. The ultimate goal is to effectively support the requirements of the users. TechTIDE has set the frame and the work progresses as more results are stored in the system archive.

The TechTIDE methodologies are able to detect in realtime activity caused by both large-scale and medium-scale TIDs and characterize background conditions and external drivers, as an additional information required by the users to assess in real time the criticality of the ongoing disturbances. These methodologies are based on the exploitation of data collected in real time from Digisondes, GNSS receivers and CDSS networks. The results of the data analysis are obtained and distributed in real time. The calculated TID characteristics and the products available and distributed by the TechTIDE warning system are summarized in Table 1.

Further improvements are expected from the simultaneous application of the TID detection methodologies in Europe and South Africa and collection of simultaneous results for TID activity, to better estimate the probability for TID interhemispheric circulation and its effects. Case studies of past events performed within the TechTIDE project (Watermann, 2020) indicate that during geomagnetic storms, even if of moderate magnitude, one may expect with rather high likeliness TIDs to be launched at auroral latitudes in both hemispheres which propagate equatorward. If LSTIDs are launched in one hemisphere during the main or early recovery phases of a geomagnetic storm it is almost certain that LSTIDs are simultaneously launched in the other hemisphere. Interhemispheric circulation of TIDs (i.e. propagation across the equator from one hemisphere into the other) was also observed in a few cases, 
a
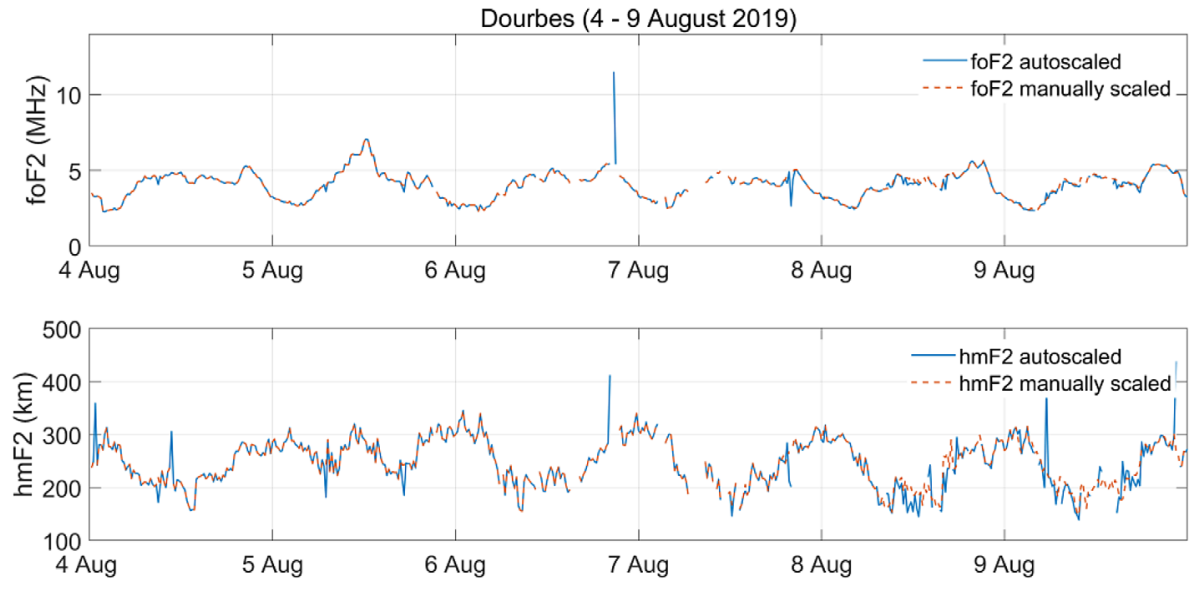

b
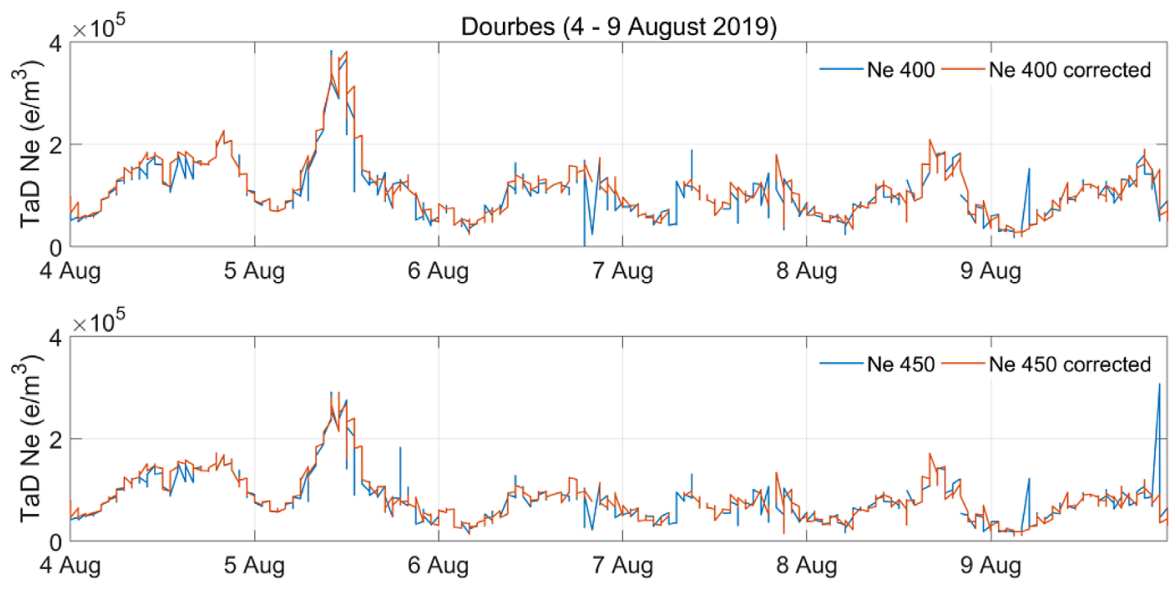

Fig. 11. (a) The autoscaled values of the foF 2 and hmF2 ionospheric characteristics (blue line) obtained over Dourbes in comparison to manually scaled ones (red dashed line) for the time interval 4-9 August 2019. (b) Results of the TaD algorithm in the topside ionosphere (400 and $450 \mathrm{~km}$ ) with autoscaled (blue line) and manually scaled (red line) foF2 and hmF2 values as input.

but such events constituted a minority. Balthazor \& Moffett (1997) employed the CTIP (Coupled Thermosphere-Ionosphere-Plasmasphere) model (Millward et al., 1996) to simulate propagation of TIDs on a global scale. According to their numerical results all TID modes interfere constructively at the magnetic equator and continue their propagation into the opposite hemisphere. However, only few actual observations of AGW or TID crossing the equator and subsequently propagating into the other hemisphere were reported in the literature (Ding et al., 2008; Bowman \& Mortimer, 2011; Guo et al., 2014, 2015; Pradipta et al., 2016).

We investigated 26 event periods lasting between $4 \mathrm{~h}$ and $15 \mathrm{~h}$ each, the majority of which took place during geomagnetic storms. The analysis revealed that during the main and early recovery phases of strong storms with Dst $<-90$ nT LSTID are almost always launched in both hemispheres. But very few of them were observed to cross the geomagnetic equator and continue their way into the opposite hemisphere. An example is shown in Figure 10.

The data coverage is, unfortunately, poor in the vicinity of the geomagnetic equator and up to $25^{\circ}$ geographic north. This latitude band corresponds to Central and sub-Sahara Africa and suffers from the low density of reliable and accessible research quality GNSS receivers. Table 2 shows the results in a quantitative manner. Observations, method and results are described in more detail in the TechTIDE report D3.4 an updated version of which is publicly available (Watermann, 2020).

Additional enhancements are expected with the integration of results from supplementary methods to further support specification of TID activity with better confidence. In this framework, the height-time-reflection intensity (HTI) method is considered, first proposed by Haldoupis et al. (2006). The application of this method in the frames of the project will enable the identification and tracking of the TID activity over each Digisonde station by using the actual ionograms produced over each station. This technique considers an ionogram a "snapshot" of intensity and height as a function of Digisonde frequency, and uses a sequence of ionograms to compute an average HTI plot, (for a given frequency bin) that is essentially a 3-D plot of reflected signal-to-noise ratio as a function of height within a given time interval.

Following the implementation of the TechTIDE methodologies, the key challenges for the development of a reliable realtime TID warning system are: (a) the quality of ingested data, and (b) a better specification of the activity levels in correlation with performance degradation data from operations systems concerned. 
(a) The quality of the data ingested into TechTIDE algorithms strongly affects the accuracy and reliability of the results. Note that the results shall be driven by real-time input that in several cases suffers from occasional errors, as for instance data spikes or outliers. These errors may be attributed to measurement errors or raw data processing errors. As an indicative example of relevant cases one may consider the Digisonde-derived ionospheric characteristics that serve as input to some of the methodologies (e.g., LSTIDx and HF-INT). The real-time implementation of the algorithms is based on the exploitation of the automatically scaled ionograms. Although previous studies of the quality of specific autoscaling algorithms suggest their excellent overall compatibility with the manual scaling at selected ionosonde stations (Galkin et al., 2008), the autoscaled values may still occasionally be dramatically wrong, thus contributing errors to the algorithms' output. Figure 11a presents the autoscaled values of the foF 2 and $h m F 2$ ionospheric characteristics obtained over Dourbes in comparison to manually scaled ones for the time interval 4-9 August 2019 to indicate the occurrence of data outliers in the autoscaled characteristics. The respective effect of the data errors in TaD's performance that is related to LSTIDx performance is investigated in Figure $11 \mathrm{~b}$. It is clear, that data quality control should be anticipated in any future upgrade of the TechTIDE warning services to ensure reliability of the results in all possible cases. Since any operational implementation cannot rely on manually scaled data, the development of data filtering algorithms may be envisaged, which apart from data outliers, will partially address data gaps issues.

(b) The next big challenge in future developments is the scaling of TID activity and characterization of the criticality of the induced disturbances in the systems concerned. Significant progress has been made in TechTIDE, especially for the correlation of the AATR and MSTID $_{\text {idx }}$ indices with performance degradation data from the EGNOS and N-RTK system respectively (Juan et al., 2019). Indicatively, a preliminary AATR analysis has shown inverse correlation between the AATR values and the EGNOS availability. This correlation was also observed between AATR and the horizontal protection level (HPL) and vertical protection level (VPL) values as an increase of the AATR values leads to an increase of the protection levels (xPL). However, the AATR tends to present different distributions for different locations, so for the use of AATR as an indicator of ionospheric activity, different AATR values should be defined at different latitudinal zones. Moreover, the results show that the presence of MSTIDs degrades the user positioning in both RTK and NRTK services. This degradation is not only related to the effect of the TID on the user measurements but in the measurements of any of the reference receivers. The analysis has shown that it is possible to implement the MSTID index as a tool to mitigate positioning degradation (Juan et al., 2019). It has been clearly demonstrated that TIDs can have multiple effects in the operation of aerospatial and ground-based infrastructures and especially in EGNOS and N-RTK services, in high frequency (HF) communications, in radio reconnaissance operations and in very high frequency - ultra high frequency (VHFUHF) radiowave propagation. The real-time identification of perturbations induced in the ionospheric characteristics is a strong requirement from all operation sectors concerned.

Promising developments could also be envisaged through the exploitation of TechTIDE detection algorithms to develop new methodologies able to provide a probability of TID occurrence well in advance. This task should include also the analysis of TID drivers that are physical mechanisms corresponding to solar X rays, solar protons, solar wind, interplanetary magnetic field structures at L1, high-latitude ionospheric electric fields, auroral electron precipitation, the ring current the magnetospheric electron fluxes and the ionospheric convection pattern. Furthermore, the TechTIDE results also indicate that CMEs, as well as CIR/CH HSS are very efficient sources of TIDs. Although further research is needed on using empirical methods (e.g. time delay in ionospheric response, season and latitudinal dependence, interhemispheric circulation) and gather more data for statistical analysis (e.g., amplitudes and periods vs. solar wind speed, duration of TID activity), it may be expected that ionospheric models which depend on solar wind and magnetospheric conditions, such as the SWIF model (Tsagouri et al., 2009), can be considered to provide short-term forecasted conditions for the next $24 \mathrm{~h}$ including TID occurrence.

Finally, we note that the source code of all TID detection methods is available for downloading from the TechTIDE repository (at http://tech-tide.eu) under the Creative Commons Attribution License.

Acknowledgements. The TechTIDE project has received funding from the European Union's Horizon 2020 research and innovation programme under grant agreement no. 776011. $\mathrm{AB}$ acknowledges financial support provided by the AFRL grant award FA9550-19-1-7019. IT and KT acknowledge support of this work by the project "PROTEAS II" (MIS 5002515), which is implemented under the Action "Reinforcement of the Research and Innovation Infrastructure", funded by the Operational Programme "Competitiveness, Entrepreneurship and Innovation" (NSRF 2014-2020) and co-financed by Greece and the European Union (European Regional Development Fund). The IL and IU indicators are retrieved from the IMAGE web site of FMI. JW owes special thanks to Zama Katamzi-Joseph, South African Space Agency SANSA, for processing a substantial amount of GNSS data and producing DTEC maps to support the LSTID analysis which led to Table 2. The editor thanks Paulo Fagundes and an anonymous reviewer for their assistance in evaluating this paper.

\section{References}

Altadill D, Belehaki A, Blanch E, Borries C, Buresova D, Chum J, Galkin I, Haralambous H, Juan Zornoza JM, Kutiev I, Oikonomou C, Sanz Subirana J, Segarra A, Tsagouri I. 2019. Report on the design and specifications of the TID algorithms and products. https://doi.org/10.5281/zenodo.2590419. 
Altadill D, Segarra A, Blanch E, Juan JM, Paznukhov VV, Buresova D, Galkin I, Reinisch BW, Belehaki A. 2020a. A method for realtime identification and tracking of traveling ionospheric disturbances using ionosonde data: First results. J Space Weather Space Clim 10: 2. https://doi.org/10.1051/swsc/2019042.

Altadill D, Belehaki A, Blanch E, Buresova D, Tsagouri I, Juan Zornoza JM, Timoté C, Borries C, Galkin I, Haralambous H, Mielich J. 2020b. Report on TID activity metrics. https://doi.org/ 10.5281/zenodo.3837357

Azeem I, Yue J, Hoffmann L, Miller SD, Straka WC III, Crowley G. 2015. Multisensor profiling of a concentric gravity wave event propagating from the troposphere to the ionosphere. Geophys Res Lett 42: 7874-7880. https://doi.org/10.1002/2015GL065903.

Balthazor RL, Moffett RJ. 1997. A study of atmospheric gravity waves and travelling ionospheric disturbances at equatorial latitudes. Ann. Geophys 15: 1048-1056. https://doi.org/10.1007/ s00585-997-1048-4.

Belehaki A, Kutiev I, Marinov P, Tsagouri I, Koutroumbas K, Elias P. 2017. Ionospheric electron density perturbations during the 7-10 March 2012 geomagnetic storm period. Adv Space Res 59(4): 1041-1056. https://doi.org/10.1016/j.asr.2016.11.031.

Belehaki A, Reinisch B, Galkin I, Altadill D, Buresova D, Francis M, Mielich J, Paznukhov V, Stankov S. 2015. Pilot network for identification of travelling ionospheric disturbances. In: Proceedings of the 14th International Ionospheric Effects Symposium, pp. 284-291. http://ies2015.bc.edu/wp-content/uploads/2015/08/ IES2015-Proceedings.pdf.

Belehaki A, Tsagouri I. 2002. Investigation of the relative bottomside/topside contribution to the total electron content estimates. Ann Geophys 45(1): 73-86. https://doi.org/10.4401/ag-3498.

Belehaki A, Tsagouri I, Kutiev I, Marinov P, Fidanova S. 2012. Upgrades to the topside sounders model assisted by Digisonde $(\mathrm{TaD})$ and its validation at the topside ionosphere. J Space Weather Space Clim 2: A20. https://doi.org/10.1051/swsc/2012020.

Beley VS, Galushko VG, Yampolski YM. 1995. Traveling ionospheric disturbance diagnostics using HF signal trajectory parameter variations. Radio Sci 30(6): 1739-1752. https://doi.org/ 10.1029/95RS01992.

Borries C, Jakowski N, Kauristie K, Amm O, Mielich J, Kouba D. 2017. On the dynamics of large-scale travelling ionospheric disturbances over Europe on 20th November 2003. J Geophys Res 122: 1199-1211. https://doi.org/10.1002/2016JA023050.

Bowman GG, Mortimer IK. 2011. Some aspects of large-scale travelling ionospheric disturbances which originate at conjugate locations in auroral zones, cross the equator and sometimes encircle the Earth. Ann Geophys 29: 2203-2210. https://doi.org/ 10.5194/angeo-29-2203-2011.

Buresova D, Belehaki A, Tsagouri I, Watermann J, Galkin I, Altadill D, Blanch E, Chum J, Sindelarova T, Kouba D, Borries C, Habarulema JB, Katamzi Z, Haralambous H, Verhulst T, Mielich J. 2018. Report on methodology for the specification of additional parameters. https://doi.org/10.5281/zenodo.2555119.

Chum J, Podolská K. 2018. 3D analysis of GW propagation in the ionosphere. Geophys Res Lett 45: 11562-11571. https://doi.org/ 10.1029/2018GL079695.

Ding F, Wam W, Liu L, Afraimovich EL, Voeykov SV, Perevalova NP. 2008. A statistical study of large-scale traveling ionospheric disturbances observed by GPS TEC during major magnetic storms over the years 2003-2005. J Geophys Res 113: A00A01. https://doi.org/10.1029/2008JA013037.

Figueiredo CAOB, Wrasse CM, Takahashi H, Otsuka Y, Shiokawa K, Barros D. 2017. Large-scale traveling ionospheric disturbances observed by GPS dTEC maps over North and South
America on Saint Patrick's Day storm in 2015. J Geophys Res Space Phys 122: 4755-4763. https://doi.org/10.1002/2016JA023417.

Francis SH. 1975. Global propagation of atmospheric gravity waves: A review. J Atmos Sol-Terr Phys 37(6-7): 1011-1054. https://doi. org/10.1016/0021-9169(75)90012-4.

Galkin IA, Reinisch BW, Huang X, Paznukhov VV. 2008. Uncertainty and Confidence of Ionospheric Specifications with the Digisonde ARTIST-5 Ionogram Autoscaler. In: Proc. IES-2008, Alexandria, VA, May 13-15, 2008, pp. 450-457

Guo J, Forbes JM, Wei F, Feng X, Liu H, Wan W, Yang Z, Liu C, Emery BA, Deng Y. 2015. Observations of a large-scale gravity wave propagating over an extremely large horizontal distance in the thermosphere. Geophys Res Lett 42: 6560-6565. https://doi. org/10.1002/2015GL065671.

Guo J, Liu H, Feng X, Wan W, Deng Y, Liu C. 2014. Constructive interference of large-scale gravity waves excited by interplanetary shock on 29 October 2003: CHAMP observation. J Geophys Res 119: 6846-6851. https://doi.org/10.1002/2014JA020255.

Habarulema JB, Katamzi ZT, Yizengaw E. 2015. First observations of poleward large-scale traveling ionospheric disturbances over the African sector during geomagnetic storm conditions. J Geophys Res 120: 6914-6929. https://doi.org/10.1002/2015JA021066.

Habarulema JB, Katamzi ZT, Yizengaw E, Yamazaki Y, Seemala G. 2016. Simultaneous stormtime equatorward and poleward largescale TIDs on a global scale. Geophys Res Lett 43: 6678-6686. https://doi.org/10.1002/2016GL069740.

Habarulema JB, Yizengaw E, Katamzi-Joseph ZT, Moldwin MB, Buchert S. 2018. Storm time global observations of large-scale TIDs from ground-based and in situ satellite measurements. J Geophys Res 123: 711-724. https://doi.org/10.1002/2017JA024510.

Haldoupis C, Meek C, Christakis N, Pancheva D, Bourdillon A. 2006. Ionogram height-time-intensity observations of descending sporadic E layers at mid-latitude. J Atmos Sol-Terr Phys 68: 539557. https://doi.org/10.1016/j.jastp.2005.03.020.

Hernández-Pajares M, Juan JM, Sanz J. 2006. Medium scale traveling disturbances affecting GPS measurements: Spatial and temporal analysis. JGR 111: A07-S11. https://doi.org/10.1029/ 2005JA011474.

Hocke K, Schlegel K. 1996. A review of atmospheric gravity waves and travelling ionospheric disturbances. Ann Geophys 14(917): 1996. https://doi.org/10.1007/s00585-996-0917-6.

Hooke WH. 1968. Ionospheric irregularities produced by internal atmospheric gravity waves. J Atmos Sol-Terr Phys 30: 795-823. https://doi.org/10.1016/S0021-9169(68)80033-9.

Huang X, Reinisch BW, Sales GS, Paznukhov VV, Galkin IA. 2016. Comparing TID simulations using 3-D ray tracing and mirror reflection. Radio Sci 51: 337-343. https://doi.org/10.1002/ 2015RS005872.

Hunsucker RD. 1982. Atmospheric gravity waves generated in the high-latitude ionoshpere: A review. Rev Geophys Space Phys 20 (2): 293-315. https://doi.org/10.1029/RG020i002p00293.

Jayachandran B, Balan N, Nampoothiri SP, Rao PB. 1987. HF Doppler observations of vertical plasma drifts in the evening $\mathrm{F}$ region at the equator. $J$ Geophys Res 92(A10): 11253-11256. https://doi.org/10.1029/JA092iA10p11253.

Juan JM, Sanz J, González-Casado G, Timoté C, Tölle J, Magdaleno S, Rupiewicz J, Mielich J. 2019. Statistical analysis of the results: Assessment of the impact on aerospace and ground systems. https://doi.org/10.5281/zenodo.3453687.

Juan JM, Sanz J, Rovira-Garcia A, González-Casado G, Ibáñez D, Orus Perez R. 2018. AATR an ionospheric activity indicator specifically based on GNSS measurements. J Space Weather Space Clim 8(2018): A14. https://doi.org/10.1051/swsc/2017044. 
Kutiev I, Marinov P, Belehaki A. 2016. Real time 3-D electron density reconstruction over Europe by using TaD profiler. Radio Sci 51: 1176-1187. https://doi.org/10.1002/2015RS005932.

Kutiev I, Marinov P, Fidanova S, Belehaki A, Tsagouri I. 2012. Adjustments of the $\mathrm{TaD}$ electron density reconstruction model with GNSS TEC parameters for operational application purposes. J Space Weather Space Clim 2: A21. https://doi.org/10.1051/swsc/ 2012021.

Kutiev I, Marinov P, Watanabe S. 2006. Model of topside ionosphere scale height based on topside sounder data. Adv Space Res 37(5): 943-950. https://doi.org/10.1016/j.asr.2005.11.021.

Lastovicka J. 2006. Forcing of the ionosphere by waves from below. J Atmos Sol-Terr Phys 68: 479-497. https://doi.org/10.1016/ j.jastp.2005.01.018.

Lastovicka J, Chum J. 2017. A review of results of the international ionospheric Doppler sounder network. Adv Space Res 60(8): 1629-1643. https://doi.org/10.1016/j.asr.2017.01.032.

Mayr HG, Harris I, Herrero FA, Spencer NW, Varosi F, Pesnell WD. 1990. Thermospheric gravity waves - Observations and interpretation using the transfer function model (TFM). Space Sci Rev 54: 297-375. https://doi.org/10.1007/BF00177800.

Mevius M, van der Tol S, Pandey VN, Vedantham HK, Brentjens MA, et al. 2016. Probing ionospheric structures using the LOFAR radio telescope. Radio Sci. 51: 927-941. https://doi.org/10.1002/ 2016RS006028.

Millward GH, Moffett RJ, Quegan S, Fuller-Rowell TJ. 1996. A coupled thermosphere-ionosphere-plasmasphere model CTIP. In: STEP handbook on ionospheric models, Schunk RW (Ed.), Utah State University, Logan, UT, p. 239.

Morgan MG, Ballard KA. 1978. The height dependence of wavenormal depression and disturbance amplitude in TID's. $J$ Geophys Res 83(A12): 5741-5744. https://doi.org/10.1029/JA083iA12p05741.

Nickisch LJ, Fridman S, Hausman M, San Antonio GS. 2016. Feasibility study for reconstructing the spatial temporal structure of TIDs from high resolution backscatter ionograms. Radio Sci 51: 443-453. https://doi.org/10.1002/2015RS005906.

Paznukhov VV, Galushko VG, Reinisch BW. 2012. Digisonde observations of AGWs/TIDs with frequency and angular sounding technique. Adv Space Res 49(4): 700-710. https://doi.org/10.1016/ j.asr.2011.11.012.

Pintor P, Roldán R, Gomez J, de La Casa C, Fidalgo RM. 2015. The impact of the high ionospheric activity in the EGNOS performance. Coord Mag XI(3), 20-28.

Pradipta R, Valladares CE, Carter BA, Doherty PH. 2016. Interhemispheric propagation and interactions of auroral traveling ionospheric disturbances near the equator. J Geophys Res Space Phys 121: 2462-2474. https://doi.org/10.1002/2015JA022043.

Reinisch B, Galkin I, Belehaki A, Paznukhov V, Huang X, et al. 2018. Pilot ionosonde network for identification of traveling ionospheric disturbances. Radio Sci 53: 365-378. https://doi.org/ 10.1002/2017RS006263.

Ross W. 1947. The estimation of the probable accuracy of high frequency radio direction-finding bearings. $J$ IEE 94(Part III): 722-726. https://doi.org/10.1049/ji-3a-2.1947.0092.

Sanz J, Juan JM, González-Casado G, Prieto-Cerdeira R, Schlueter S, Orús R. 2014. Novel ionospheric activity indicator specifically tailored for GNSS users. In: Proceedings of ION GNSS+ 2014. Tampa, Florida (USA), pp. 1173-1182. http://www.ion.org/publications/ abstract.cfm?jp=p\&articleID $=12269$.

Sauli P, Boska J. 2001. Tropospheric events and possible related gravity wave activity effects on the ionosphere. J Atmos Sol-Terr Phys 63: 945-950.

Savastano G, Komjathy A, Verkhoglyadova O, Mazzoni A, Crespi M, Wei Y, Mannucci AJ. 2017. Real-time detection of tsunami ionospheric disturbances with a stand-alone GNSS receiver: A preliminary feasibility demonstration. Sci Rep 7: 46607. https://doi.org/10.1038/srep46607.

Tsagouri I, Belehaki A, Koutroumbas K. 2018a. Models for the specification of ionospheric background, Zenodo. https://doi.org/ 10.5281/zenodo.3929555.

Tsagouri I, Goncharenko L, Shim JS, Belehaki A, Buresova D, Kuznetsova MM. 2018b. Assessment of current capabilities in modeling the ionospheric climatology for space weather applications: foF2 and hmF2. Space Weather 16: 1930-1945. https://doi. org/10.1029/2018SW002035.

Tsagouri I, Koutroumbas K, Belehaki A. 2009. Ionospheric foF2 forecast over Europe based on an autoregressive modeling technique driven by solar wind parameters. Radio Sci 44: RS0A35. https://doi.org/10.1029/2008RS004112.

Tsagouri I, Koutroumbas K, Elias P. 2018c. A new short-term forecasting model for the total electron content storm time disturbances. J Space Weather Space Clim 8: A33. https://doi. org/10.1051/swsc/2018019.

Tsugawa T, Saito A. 2004. A statistical study of large-scale traveling ionospheric disturbances using the GPS network in Japan. $J$ Geophys Res 109: A06302. https://doi.org/10.1029/2003JA010302.

Watermann J. 2020. Methodology for the identification of the interhemispheric circulation (version 1.2). TechTIDE Project Report. https://doi.org/10.5281/zenodo.4019014.

Xiao Z, Xiao SG, Hao YQ, Zhang DH. 2007. Morphological features of ionospheric response to typhoon. J Geophys Res 112: A04304. https://doi.org/10.1029/2006JA011671.

Zhang S-R, Coster AJ, Erickson PJ, Goncharenko LP, Rideout W, Vierinen J. 2019. Traveling ionospheric disturbances and ionospheric perturbations associated with solar flares in September 2017. J Geophys Res Space Phys 124: 5894-5917. https://doi.org/ 10.1029/2019JA026585.

Cite this article as: Belehaki A, Tsagouri I, Altadill D, Blanch E, Borries C, et al. 2020. An overview of methodologies for real-time detection, characterisation and tracking of traveling ionospheric disturbances developed in the TechTIDE project. J. Space Weather Space Clim. 10, 42. https://doi.org/10.1051/swsc/2020043. 